\title{
EFICIÊNCIA DOS GASTOS MUNICIPAIS EM EDUCAÇÃOO NO PARANÁ
}

EFFICIENCY OF MUNICIPAL EXPENDITURE ON EDUCATION IN PARANÁ

Recebido em 25.10.2018. Aprovado em 30.10.2018

Avaliado pelo sistema double blind review

DOI: http://dx.doi.org/10.12712/rpca.v12i4.27149

\section{Wanderson Dutra Gresele}

wanderson.gresele@hotmail.com

Universidade Estadual do Oeste do Paraná (UNIOESTE), Marechal Cândido Rondon/PR, BRASIL

ORCID: https://orcid.org/0000-0002-5002-6909

\section{Franklin Angelo Krukoski}

franklin.krukoski@gmail.com

Universidade Estadual do Oeste do Paraná (UNIOESTE), Francisco Beltrão/PR, BRASIL

ORCID: https://orcid.org/0000-0003-2086-7456

\section{Resumo}

A presente pesquisa teve como objetivo avaliar a eficiência dos gastos públicos no ensino fundamental nos municípios do Estado do Paraná no ano de 2015. Para tal, utilizou-se da técnica de análise envoltória de dados (DEA), análise de correlações, análise de agrupamentos e testes de comparações de médias. Quanto aos resultados, apenas 13 municípios, dos 389 analisados, foram enquadrados como eficientes; constatou-se um relacionamento negativo fraco entre os investimentos em educação e escolas e positivo com docentes; a eficiência possui um relacionamento negativo forte com investimentos e escolas e negativo fraco com docentes, bem como um relacionamento positivo fraco com o IDEB; identificou também quatro grupos distintos de municípios, uma vez que alguns municípios alcançaram melhores resultados com menores aportes de recursos e outros que, mesmo realizando um significativo aporte de recursos, não apresentaram resultados à altura.

Palavras-chave: Educação. Eficiência. Análise Envoltória de Dados. Municípios. Paraná.

\section{Abstract}

The present study aimed to evaluate the efficiency of public investments in elementary education in the Paranás counties in 2015. For that, techniques of data envelopment analysis (DEA), correlation analysis, clustering analysis and tests of means comparisons were used. Regarding the results, of the 389 only 13 counties were efficient; found a weak negative relationship between investments in education and schools and positive with teachers; efficiency has a strong negative relationship with investments and schools and weak negative with teachers and a weak positive relationship with IDEB; identified four distinct groups, which indicates that some counties that achieved better results with smaller resources and others that even making a significant contribution of resources did not reach results.

Keywords: Education. Efficiency. Data Envelopment Analysis. Counties. Paraná. 


\section{Introdução}

É notório que o Brasil enfrenta sérios problemas de gestão e cuidado com o bem público (SILVA, 2010). Adicionalmente, há uma redução no investimento em políticas públicas e um aumento da demanda por serviços estatais, dado a recessão econômica vivenciada atualmente, a qual afeta a arrecadação do estado, o número de empregos e o poder aquisitivo da população entre outros (MONTE e LEOPOLDINO, 2017).

Assim, torna-se latente repensar que a qualidade dos serviços públicos é uma consequência direta do investimento de recursos. O problema central de qualquer organização, como os órgãos públicos, é a escassez e, por isso, os gestores devem conseguir o maior retorno possível dos recursos empregados. A eficiência tem a ver exatamente com isso, ou seja, a obtenção do maior benefício possível de uma quantidade de recursos escassos (MATTOS e TERRA, 2015a) e esse é desafio do Brasil (DINIZ e CORRAR, 2011; MONTE e LEOPOLDINO, 2017).

Este artigo advém da necessidade de compreender a eficiência na utilização dos insumos aplicados na educação, pois a escolarização formal é chave para o desenvolvimento econômico e social e é por isso que o Brasil vem investindo de forma contínua nesse setor (SAVIAN e BEZERRA, 2013). Num primeiro momento, o aumento significativo de recursos para a educação seria a solução, entretanto, por si só, pode não garantir melhoria no setor educacional de um país (DINIZ e CORRAR, 2011). Não há dúvida de que, em média, o total de recursos para a Educação em mãos dos governos municipais aumentou, mas estudos feitos pela Organização para a Cooperação e Desenvolvimento Económico (OCDE), através do Programa Internacional de Avaliação de Estudantes (PISA), apresenta que o cenário nacional ainda possui defasagens de nossos alunos no que concerne aos parâmetros de desempenho escolar (PEÑA, 2012; ROCHA, 2013; CASTRO e SOUSA, 2018).

Neste caminho, torna-se importante o processo de análise de eficiência, pois ele fornece uma comparação dos desempenhos de unidades tomadoras de decisões (DMU's) com aquelas que apresentam altos padrões de eficiência, permitindo detectar situações de ineficiência, ou seja, de desperdício de recurso público. Ainda, tal como indicam Savian e Bezerra (2013), é possível melhorar o desempenho dos municípios ineficientes não aumentando a quantidade de recursos empregados, porém, como apresentam Ferreira e
Gomes (2012), utilizando-os de forma mais eficiente.

Assim, o presente artigo apresentou o seguinte problema: Como se apresenta a eficiência dos gastos públicos no Ensino Fundamental nos municípios do Estado do Paraná no exercício de 2015? Logo, carregou o seguinte objetivo: avaliar a eficiência dos gastos públicos no Ensino Fundamental nos municípios do Estado do Paraná no ano de 2015. Além disso, buscou-se verificar se existe relacionamento entre os recursos aportados e o desempenho dos municípios paranaenses; como também procurou-se identificar e aportar as diferenças entre os desempenhos e recursos aportados pelos municípios.

Para o alcance do proposto objetivo, as eficiências dos municípios foram desenvolvidas por meio da técnica de análise envoltória de dados, também conhecida como DEA (Data Envelopment Analysis), com base nos investimentos financeiros por alunos, número de docentes por alunos, número de escolas por alunos e no resultado demonstrado no Índice de Desenvolvimento da Educação Básica (IDEB). Esses índices foram examinados por meio de análises de correlações, análises de agrupamentos e testes de comparações de médias.

\section{Fundamentação teórica}

\section{Educação brasileria}

Como ordena a Constituição da República Federativa do Brasil de 1988, a educação, tal como a saúde e habitação, são direitos sociais e dever do Estado. Mais propriamente no caso da educação, o artigo 211, parágrafo $2^{\circ}$ da Constituição de 1988, definiu como responsabilidade obrigatória dos municípios a atuação prioritária no Ensino Fundamental e na Educação Infantil, dando início ao processo, que ficou conhecido como municipalização do ensino (ROCHA, 2013).

Dois outros momentos são importantes para a educação brasileira no que tange ao Ensino Fundamental. O primeiro trata da Emenda Constitucional $n^{\circ} 14$, de setembro de 1996, que instituiu o FUNDEF (Fundo de Manutenção e Desenvolvimento do Ensino Fundamental e de Valorização do Magistério), o qual regulamentou o financiamento da educação pública fundamental brasileira, visto que foi criado com o intuito de reduzir as diferenças regionais, como também para estabelecer um piso para os gastos estaduais e municipais com Ensino Fundamental. O 
segundo trata da instituição do FUNDEB (Fundo de Manutenção e Desenvolvimento da Educação Básica e de Valorização dos Profissionais da Educação), que passou a vigorar em 2007 com o objetivo de contribuir para a universalização da educação básica, bem como para promover a equidade, melhorar a qualidade do ensino e valorizar os profissionais da educação. (SAVIAN e BEZERRA, 2013)

Salienta-se também que outros índices foram criados na busca de acompanhar o desenvolvimento dos alunos, como é o caso do Índice de Desenvolvimento da Educação Básica (IDEB), desenvolvido no ano de 2007. O IDEB é um indicador de qualidade educacional que combina informações de desempenho em exames padronizados com informações sobre o rendimento escolar. Em suma, a função do IDEB é sintetizar os resultados das avaliações desenvolvidas no sistema de ensino (Sistema de Avaliação da Educação Básica (SAEB) e Prova Brasil), para que possam ser assimilados mais facilmente, permitindo, assim, o estabelecimento de metas de qualidade educacional. (FERNANDES, 2007).

Como apresenta o Instituto Anísio Teixeira (INEP, 2018) o IDEB varia de zero a dez e contempla a medida de fluxo, que é o tempo de permanência do aluno no período correspondente a sua idade, e as medidas de desempenho na aprendizagem, apreendidos por meio dos dados sobre aprovação escolar, obtidos no Censo Escolar e das médias de desempenho nas avaliações do Inep, sendo o Sistema de Avaliação da Educação Básica (Saeb), para os Estados, e a Prova Brasil, para os municípios.

O IDEB apresenta-se como condutor de políticas públicas em prol da qualidade da educação, sendo uma ferramenta para acompanhamento das metas de qualidade do Plano de Desenvolvimento da Educação (PDE) para a educação básica, que tem estabelecido, como meta, que em 2022 o Brasil ultrapasse 6,0, média que corresponde a um sistema educacional de qualidade comparável a dos países desenvolvidos.

É importante reconhecer que a aprendizagem é um processo que combina vários recursos (alunos, características das escolas, fatores institucionais, dinheiro investido no setor, etc.) para gerar resultados, ou seja, isso pode ser definido como uma relação insumo/produto, podendo ser um parâmetro para avaliar a eficiência das unidades tomadoras de decisão. Assim, é possível usar o conceito de eficiência relativa, o qual padroniza os desempenhos, como no IDEB, pelos recursos empregados para o alcance de tal resultado. (ROCHA, 2013)

\section{Fatores e indices de eficiência}

A combinação de insumos e a sua transformação em produtos e serviços, dentro de um processo, é o que se pode chamar hoje de uma maneira simplista de organização. Mattos e Terra (2015) dizem que esse processo produtivo não é determinístico e, dependendo das circunstâncias de fatores, é também variável, tal como pode ser visualizado na educação. A produtividade, que é a razão entre o que foi produzido (produto) e o que foi gasto para isso (insumo), é resultado das decisões tomadas por seus gestores, relevando o quanto os recursos existentes estão sendo bem utilizados.

A primeira definição formal de produção eficiente é dada por Koopmans no ano de 1951 e metodologicamente desenvolvida por Debreu, em 1951, e Farrell, em 1957. A partir desses três marcos, sabe-se que um processo de produção é eficiente quando emprega a menor quantidade possível de insumos (inputs) para uma dada produção (output) (eficiência econômica) ou quando obtém um maior nível de produção (output) com dado nível de recursos (inputs) (eficiência técnica). (ROSANO-PEÑA, 2008, 2012; BOUERI, 2015; PASCOTTO, COMUNELO E CERETTA, 2018)

Para o processo de análise, os modelos de análise de eficiência podem ser classificados em dois grandes grupos: os paramétricos e os não paramétricos. Os modelos de análise paramétricos avaliam a eficiência por uma relação funcional entre os recursos utilizados e a quantidade máxima de produtos produzidos, a partir dos parâmetros dessa função produção. Já as técnicas não paramétricas de análise da eficiência, como é o caso da Análise Envoltória de Dados (DEA), assumem hipóteses mais flexíveis sobre a distribuição das variáveis e não exigem a especificação de uma função entre insumos e produtos (ROSANO-PEÑA, 2012).

O desenvolvimento prático da técnica de Análise Envoltória de Dados se deu no ano de 1978 com a tese de doutorado de Edward Rhodes, que teve a orientação de Willian Wager Cooper, a qual tinha como ideia a comparação do desempenho dos alunos de escolas que participavam de um programa federal 
de apoio com escolas que não aderiram ao programa. Cooper então utilizou-se do método de programação matemática, partindo do conceito de eficiência técnica em casos de produto/insumo, desenvolvido por Farrel no ano de 1957, para a construção de um modelo que atendesse vários produtos e insumos para medir e comparar o desempenho das escolas.

O modelo inicial do DEA, desenvolvido pelos autores Charnes, Cooper e Rhodes (1978), denominado de CCR, pressupõe retornos constantes de escala, isso quer dizer que uma variação nos inputs produz uma mudança equiproporcional nos outputs. De outra maneira, um aumento de $\mathrm{k} \%$ na utilização de todos os insumos aumenta os resultados na mesma proporção de $\mathrm{k} \%$ (BOUERI, 2015, MATTOS e TERRA, 2015b).

Entretanto, é possível que uma função de produção apresente outros tipos de retornos de escala, além do retorno constante, ou seja, dependendo da quantidade de insumos que esteja sendo empregada para fins de produção, uma DMU pode estar operando em retornos crescentes, decrescentes ou constantes. Se um aumento de $\mathrm{k} \%$ na utilização de todos os insumos aumenta o produto em mais do que $\mathrm{k} \%$, dizemos que a função de produção apresenta retornos crescentes à escala. Entretanto, se esse mesmo aumento produzir uma variação no produto menor do que $\mathrm{k} \%$, dizemos que a tecnologia de produção apresenta retornos decrescentes à escala. (MATTOS e TERRA, 2015b).

Entendendo que algumas unidades tomadoras de decisões poderiam operar com retornos variáveis, ou seja, não apenas constantes, mas podendo ser crescentes ou decrescentes, Banker, Charnes e Cooper, no ano de 1984, apresentaram um modelo que inclui retornos variáveis de escala. Esse modelo ficou conhecido como BCC, em menção aos autores.

Comparativamente, os modelos CCR e BCC podem trazer resultados divergentes pois uma DMU por ser eficiente pelo BCC, mas não pelo CCR. Isso ocorre, porque, o modelo CCR calcula a eficiência total, enquanto o modelo BCC calcula a eficiência técnica. Para se calcular a Eficiência de Escala, divide-se a Eficiência do modelo CCR (eficiência total) pela Eficiência do modelo BCC (eficiência técnica).

Ainda, a ineficiência de determinada DMU pode ser estimada pela magnitude da projeção necessária para que ela alcance a referida fronteira (alvo). Essa projeção, que pode ser uma contração dos insumos ou uma expansão dos produtos, é realizada de forma proporcional. Por esse motivo, é denominada projeção radial, pois sempre pode ser expressa como um raio partindo da origem. (BOUERI, 2015, MATTOS e TERRA 2015b, PASCOTTO, COMUNELO e CERETTA, 2018; FERREIRA e GOMES, 2009).

\section{Análise da eficiência da educação por meio da dea}

Como já constatado por Lourenço et al. (2017), Castro e Souza (2018) e Monte e Leopoldino (2017), estudos que utilizam da eficiência por meio da aplicação do método de Análise Envoltória de Dados (DEA) tem sido amplamente utilizado para avaliar a utilização dos investimentos públicos em educação.

Lourenço et al. (2017) apontam que os municípios com melhor estrutura, localizados em regiões com melhor desenvolvimento econômico e que apresentam um melhor desempenho no IDEB não são considerados eficientes, uma vez que, estes municípios poderiam apresentar melhores resultados por possuírem estruturas melhores e mais investimentos por aluno. Ainda, os autores indicam que o percentual de eficiência é muito baixo e $85 \%$ dos municípios analisados são classificados como ineficientes. Os índices mostram que maiores gastos públicos não têm gerado melhor qualidade na educação, pois gastos e notas do IDEB não tem apresentado uma relação positiva. Entretanto, a ineficiência indica a possibilidade de melhorias, ou seja, deve-se reconhecer que municípios ineficientes têm potencial para melhorar a qualidade da educação, desde que se trabalhe em prol de melhorias na gestão dos recursos.

Para uma melhor compreensão do objeto em estudo, desenvolveu-se uma busca de artigos acadêmicos que tratam da eficiência dos gastos públicos em educação por meio da análise envoltória de dados. A relação dos artigos com seus respectivos objetivos, dados analisados, inputs e outputs e principais resultados é apresentada no Quadro 01.-

Pode-se dar destaque a duas pesquisas que tratam dos municípios do estado do Paraná. A primeira diz respeito ao estudo de Bezerra e Savian (2013), o qual avaliou a eficiência dos gastos públicos com a educação nas séries iniciais do Ensino Fundamental nos municípios paranaenses nos anos de 2005 e 2009, através da aplicação da técnica Análise Envoltória de Dados (DEA). Para esse estudo, utilizaram-se os inputs (insumos) Produto Interno Bruto (PIB) per 
capita municipal; a relação de despesa por aluno matriculado no Ensino Fundamental; o número de escolas municipais de Ensino Fundamental e a relação aluno e professor; e, como output (produto), o Índice de Desenvolvimento da Educação Básica, que é uma variável representativa de desempenho da educação. Quantos aos resultados, percebe-se que um melhor desempenho econômico não é fator decisivo para a eficiência, que os gastos com educação nos anos iniciais do Ensino Fundamental, na maioria dos municípios do Estado do Paraná, apresentaram ineficiência moderada e, ainda, percebeu-se uma redução do número de municípios eficientes entre os anos de 2005 e 2009. (BEZERRA E SAVIAN, 2013).

O segundo estudo destacado foi desenvolvido por Bohrer, Comunelo e Godarth (2013) e teve o objetivo de investigar a eficiência dos gastos públicos com a educação referente ao ano de 2009, nas 42 cidades do Sudoeste do Paraná. Foi aplicada a Análise Envoltória de Dados (DEA) com os seguintes inputs: despesas públicas liquidadas da área da Educação Básica municipal; número de alunos matriculados no Ensino Básico e gasto por aluno; já como output, utilizou-se o score da Prova Brasil, constituído pela média das provas de Matemática e Português e pela a média geral de cada município. $\mathrm{O}$ estudo apresenta que o município com a melhor eficiência nos gastos públicos é Barracão, seguido de Ampére e Capanema. Os municípios com o menor índice de eficiência foram Pinhal de São Bento, Manfrinópolis e Saudades do Iguaçu, ocupando os três últimos lugares, respectivamente. Salienta-se, também, que os municípios que possuem os maiores custos por aluno, não figuram nas primeiras posições da eficiência na gestão dos gastos com educação.

\section{Método}

A abordagem deste levantamento envolveu todos os municípios do estado do Paraná. As pesquisas foram realizadas nas seguintes fontes de dados: Declarações de Contas Anuais, obtidos no site do Sistema de Informações Contábeis e Fiscais do Setor Público Brasileiro, SICONFI, da Secretaria do Tesouro Nacional, referente ao exercício de 2015; nos dados demográficos do Ensino Fundamental nos Anos Iniciais das Escolas Municipais do Estado do Paraná, por meio do Censo do Ensino Fundamental do ano de 2015, desenvolvido pelo Ministério da Educação; e nos Índices de Desenvolvimento da Educação Básica (IDEB) dos municípios .
A análise da eficiência dos municípios se deu por meio da técnica de Análise Envoltória de Dados (DEA). O modelo BCC foi escolhido por permitir a comparar unidades tomadoras de decisões com portes diferentes. Quanto à orientação do modelo, o presente estudo utilizou-se de uma orientação para os insumos (inputs).

A técnica de seleção de dados, seguindo a literatura que trata da Análise Envoltória de Dados, utilizouse de dados semelhantes e que contemplasse a todos os municípios para definir inicialmente os inputs e outputs. A princípio, como output, o índice escolhido foi o IDEB do município e, como input, foram utilizados o gasto por aluno, docentes por alunos $\mathrm{e}$ escolas por alunos. Após, seguiu-se o pressuposto de que a seleção das variáveis deve obedecer ao princípio de máxima relação causal entre inputs e outputs, então, o método optado foi I-O Stepwise Exaustivo Completo, conforme as orientações de Senra, Mello e Meza (2007). Com isso, pode-se comprovar que o modelo é adequado.

Para o desenvolvimento das análises foram utilizados os softwares R, SPSS e QGIS. Para a Análise Envoltória de Dados, utilizou-se o software $\mathrm{R}$, livre e open source, por possuir pacotes para a análise de eficiência por meio da DEA. Destaca-se o pacote Benchmarking, como sendo esse o principal recurso computacional utilizado neste trabalho. Vale mencionar que a DEA foi desenvolvida para analisar a eficiência total, eficiência técnica e eficiência de escala das unidades tomadoras de decisões, ou seja, os municípios. (BOGETOFT e OTTO, 2011)

$\mathrm{Na}$ sequência, com os escores das eficiências, os inputs e o output, utilizou-se o software SPSS, o qual é um software de pacotes estatísticos, com o objetivo de analisar correlações entre as variáveis estudadas, bem como analisar agrupamentos e comparar os grupos formados (HAIR, 2009; FIELD, 2009; DANCEY e REIDY, 2013).

O QGis é um software livre e open source, multiplataforma de sistema de informação geográfica que permite a visualização, edição e análise de dados georreferenciados. Desta forma, como o objetivo de se ter uma melhor representação dos dados, utilizandose das coordenadas vetoriais disponíveis pelo Instituto Brasileiro de Geografia (IBGE, 2018) para o Estado do Paraná, foi desenvolvidos mapas georreferenciados de desempenho dos munícipios analisados. 
Quadro 1. Síntese dos artigos que tratam da eficiência na educação pública por meio da DEA.

\begin{tabular}{|c|c|c|c|c|}
\hline Autor(es) & Objetivo & $\begin{array}{l}\text { Dados analisados/ } \\
\text { Período }\end{array}$ & Inputs e Outputs & Principais resultados \\
\hline $\begin{array}{l}\text { Begnini e } \\
\text { Tosta (2017) }\end{array}$ & $\begin{array}{l}\text { Avaliar a eficiência dos } \\
\text { gastos com a educação } \\
\text { fundamental nos estados } \\
\text { brasileiros. }\end{array}$ & $\begin{array}{l}26 \text { estados } \\
\text { mais o Distrito } \\
\text { Federal/2011 }\end{array}$ & $\begin{array}{l}\text { Input: gastos por alunos, } \\
\text { docentes por alunos, escolas } \\
\text { por alunos. Output: IDEB } \\
\text { da } 4^{\mathrm{a}} \text { e } 8^{\mathrm{a}} \text { séries e taxa de } \\
\text { aprovação }\end{array}$ & $\begin{array}{l}\text { Resultados indicam como eficientes os } \\
\text { estados de Amazonas, Distrito Federal, São } \\
\text { Paulo, Amapá, Goiás, Minas Gerais e Acre. } \\
\text { Há necessidade de revisão nas práticas da } \\
\text { gestão em grande parte dos estados, tendo em } \\
\text { vista a melhoria contínua nos resultados. }\end{array}$ \\
\hline $\begin{array}{l}\text { Bohrer, } \\
\text { Comunelo } \\
\text { e Godarth } \\
(2013)\end{array}$ & $\begin{array}{l}\text { Investigar a eficiência dos } \\
\text { gastos públicos com a } \\
\text { educação no Sudoeste do } \\
\text { Paraná. }\end{array}$ & $\begin{array}{l}42 \text { municípios do } \\
\text { estado PR/2009 }\end{array}$ & $\begin{array}{l}\text { Inputs: custo por aluno. } \\
\text { Output: nota na Prova Brasil } \\
\text { (média nas disciplinas de } \\
\text { Português e Matemática). }\end{array}$ & $\begin{array}{l}\text { Os municípios que possuem os maiores } \\
\text { custos por aluno, não figuram nas primeiras } \\
\text { posições da eficiência na gestão dos gastos } \\
\text { com educação. }\end{array}$ \\
\hline $\begin{array}{l}\text { Castro e } \\
\text { Sousa (2018) }\end{array}$ & $\begin{array}{l}\text { Aferir os escores de } \\
\text { eficiência técnica e de escala } \\
\text { dos gastos públicos da } \\
\text { rede de ensino municipal } \\
\text { cearense. }\end{array}$ & $\begin{array}{l}149 \text { dos } 184 \\
\text { municípios } \\
\text { cearenses / } 2011\end{array}$ & $\begin{array}{l}\text { Inputs: gasto por aluno. } \\
\text { Output: número de } \\
\text { professores por aluno; } \\
\text { número de salas por aluno e } \\
\text { número de escolas por aluno. }\end{array}$ & $\begin{array}{l}\text { A utilização do recurso pela maioria dos } \\
\text { municípios cearenses se reproduz em baixa } \\
\text { eficiência técnica, indicando ser necessário } \\
\text { uma reavaliação da gestão para melhorar os } \\
\text { resultados. }\end{array}$ \\
\hline $\begin{array}{l}\text { Dantas, } \\
\text { Costa e Silva } \\
(2015)\end{array}$ & \begin{tabular}{|l|} 
Mensurar a eficiência na \\
alocação dos recursos \\
públicos oriundos do \\
FUNDEB na educação \\
fundamental dos \\
municípios do Rio Grande \\
do Norte.
\end{tabular} & $\begin{array}{l}\text { Municípios do } \\
\text { RN/2011 }\end{array}$ & $\begin{array}{l}\text { Input: professores, salas de } \\
\text { aulas e escolas por alunos } \\
\text { matriculados. Output: } \\
\text { índice do inverso da taxa } \\
\text { de distorção idade-série e o } \\
\text { índice do IDEB }\end{array}$ & $\begin{array}{l}\text { Os recursos públicos em educação } \\
\text { fundamental não são alocados de maneira } \\
\text { eficiente pelos municípios do Rio Grande } \\
\text { do Norte. O percentual de municípios que } \\
\text { atingiram a fronteira de eficiência foi de } \\
\text { apenas } 9,7 \% \text {, enquanto } 35,8 \% \text { alcançaram os } \\
\text { menores valores de eficiência na alocação de } \\
\text { recursos. }\end{array}$ \\
\hline $\begin{array}{l}\text { Diel et al. } \\
(2014)\end{array}$ & $\begin{array}{l}\text { Analisar o desempenho dos } \\
\text { municípios brasileiros com } \\
\text { mais de } 100 \text { mil habitantes } \\
\text { relacionado a sua estratégia } \\
\text { de investimentos públicos } \\
\text { em educação, } \\
\end{array}$ & $\begin{array}{l}\text { Municípios com } \\
\text { mais de } 100 \text { mil } \\
\text { habitantes, total de } \\
268\end{array}$ & $\begin{array}{l}\text { Input: valor dos gastos } \\
\text { com educação. Outputs: } \\
\text { matrículas por habitantes, } \\
\text { número de docentes e escolas } \\
\text { e a média de notas escolares. }\end{array}$ & $\begin{array}{l}\text { Pouquíssimos municípios obtiveram eficiência } \\
\text { de } 100 \% \text { ou se enquadraram em faixas de } \\
\text { score próximas ao mais eficiente. Os melhores } \\
\text { níveis foram alcançados pelo grupo formado } \\
\text { por municípios com mais de } 1 \text { milhão de } \\
\text { habitantes. }\end{array}$ \\
\hline $\begin{array}{l}\text { Diniz e } \\
\text { Corrar (2011) }\end{array}$ & $\begin{array}{l}\text { Analisar a eficiência das } \\
\text { transferências realizadas } \\
\text { pelo FUNDEB em relação } \\
\text { ao desempenho discente. }\end{array}$ & $\begin{array}{l}184 \text { municípios da } \\
\text { Paraíba/2007 }\end{array}$ & $\begin{array}{l}\text { Inputs: gastos com } \\
\text { professores/aluno e } \\
\text { gastos com estrutura de } \\
\text { funcionamento/ aluno. } \\
\text { Output: resultado da } \\
\text { proficiência em Matemática e } \\
\text { Língua Portuguesa. }\end{array}$ & $\begin{array}{l}\text { Revelaram que o aumento nas transferências } \\
\text { incondicionais e sem contrapartida não } \\
\text { é capaz de assegurar um incremento } \\
\text { na eficiência, isso não se aplica ao tipo } \\
\text { de transferências que são realizadas no } \\
\text { FUNDEF, posto que os municípios mais } \\
\text { eficientes foram aqueles que receberam } \\
\text { transferências maiores. }\end{array}$ \\
\hline $\begin{array}{l}\text { Kaveski, } \\
\text { Martins } \\
\text { e Scarpin } \\
(2015)\end{array}$ & $\begin{array}{l}\text { Identificar a eficiência dos } \\
\text { gastos públicos com o } \\
\text { Ensino Médio regular nas } \\
\text { instituições estaduais. }\end{array}$ & \begin{tabular}{l|}
27 estados \\
brasileiros, entre os \\
anos de 2005 a 2011
\end{tabular} & $\begin{array}{l}\text { Inputs: gastos com educação; } \\
\text { número de docentes; número } \\
\text { de escolas. Outputs: nota da } \\
\text { prova de Língua Portuguesa, } \\
\text { Matemática e IDEB. } \\
\end{array}$ & $\begin{array}{l}\text { A média geral da educação brasileira foi } \\
\text { estimada em } 96,38 \% . \text { Os resultados sugerem } \\
\text { que existem diferenças significativas nos } \\
\text { níveis de eficiência. }\end{array}$ \\
\hline $\begin{array}{l}\text { Lourenço et } \\
\text { al. (2017) }\end{array}$ & $\begin{array}{l}\text { Verificar se os municípios } \\
\text { brasileiros podem } \\
\text { ser diferenciados por } \\
\text { aspectos sociais, aspectos } \\
\text { econômico-financeiros e } \\
\text { de controle social, aspectos } \\
\text { pedagógicos e estruturais. }\end{array}$ & $\begin{array}{l}5.319 \text { municípios, } \\
\text { de } 2009 \text { a } 2013\end{array}$ & $\begin{array}{l}\text { Inputs: gasto médio por } \\
\text { aluno; receitas do FUNDEB; } \\
\text { PIB per capita; relação de } \\
\text { docentes/alunos; número e } \\
\text { qualificação dos professores; } \\
\text { tamanho das turmas; } \\
\text { infraestrutura escolar; IDHs. } \\
\text { Output: IDEB. } \\
\end{array}$ & $\begin{array}{l}\text { Os municípios podem ser diferenciados } \\
\text { por aspectos sociais e pedagógicos, mais } \\
\text { fortemente do que por aspectos econômicos/ } \\
\text { financeiros e de controle social. Recursos } \\
\text { financeiros em escolas municipais é } \\
\text { desimportante, sendo apenas um dos } \\
\text { elementos na promoção de uma educação de } \\
\text { qualidade }\end{array}$ \\
\hline $\begin{array}{l}\text { Lourenço et } \\
\text { al. (2017) }\end{array}$ & $\begin{array}{l}\text { Analisar a eficiência técnica } \\
\text { dos } 250 \text { maiores municípios } \\
\text { brasileiros em termos de } \\
\text { alunos matriculados no } \\
\text { Ensino Fundamental. }\end{array}$ & \begin{tabular}{|l|} 
Municípios \\
brasileiros com mais \\
alunos no período \\
de 2009 a 2013
\end{tabular} & $\begin{array}{l}\text { Inputs: despesas liquidadas; } \\
\text { gastos médios por alunos } \\
\text { do Ensino Fundamental } \\
\text { e o IDHM nas dimensões } \\
\text { educação e renda. Output: } \\
\text { IDEB. }\end{array}$ & $\begin{array}{l}\text { Apenas 5,2\% da amostra mostrou-se } \\
\text { eficiente, ao passo que } 83 \% \text { foi classificada } \\
\text { com ineficiência moderada ou forte. Os dez } \\
\text { municípios com maior nível de eficiência } \\
\text { técnica pertencem às regiões Norte e } \\
\text { Nordeste do Brasil. }\end{array}$ \\
\hline
\end{tabular}




\begin{tabular}{|c|c|c|c|c|}
\hline $\begin{array}{l}\text { Machado } \\
\text { Jr., Irffi e } \\
\text { Benegas } \\
\text { (2011) }\end{array}$ & $\begin{array}{l}\text { Avaliar a eficiência técnica } \\
\text { dos gastos municipais per } \\
\text { capita em educação, saúde } \\
\text { e assistência social para os } \\
\text { municípios cearenses. }\end{array}$ & $\begin{array}{l}67 \text { municípios do } \\
\text { CE no ano de } 2005\end{array}$ & $\begin{array}{l}\text { Inputs: gastos per capita do } \\
\text { município com educação, } \\
\text { saúde e saneamento, } \\
\text { habitação e transporte. } \\
\text { Outputs: número de } \\
\text { estabelecimentos de educação } \\
\text { infantil; taxa de alfabetização } \\
\text { de educação infantil e taxa de } \\
\text { escolarização. }\end{array}$ & $\begin{array}{l}\text { Nas áreas saúde, educação e assistência } \\
\text { social, os municípios cearenses obtiveram } \\
\text { desempenho satisfatório, haja vista que a } \\
\text { eficiência média foi de } 89 \% \text {. Analisando os } \\
\text { modelos por tipo de gasto, os resultados } \\
\text { exibem baixa eficiência dos gastos públicos } \\
\text { em saúde, educação e assistência social, os } \\
\text { quais tiveram eficiência técnica média de } 24 \% \text {, } \\
21 \% \text { e } 28 \% \text {, respectivamente. }\end{array}$ \\
\hline $\begin{array}{l}\text { Monte e } \\
\text { Leopoldino } \\
(2017)\end{array}$ & $\begin{array}{l}\text { Avaliar a eficiência dos } \\
\text { gastos em educação } \\
\text { realizados pelos municípios } \\
\text { cearenses no exercício de } \\
2015 .\end{array}$ & $\begin{array}{l}176 \text { municípios } \\
\text { cearenses/2015 }\end{array}$ & $\begin{array}{l}\text { Input: investimentos por } \\
\text { aluno. Outputs: IDEB's da } 4^{\text {a }} \\
\text { e } 8 \text { séries. }\end{array}$ & $\begin{array}{l}\text { Apenas três municípios foram considerados } \\
\text { eficientes e } 77 \% \text { atingiu índices de ineficiência } \\
\text { moderada. Foi constatada a tendência de } \\
\text { aumento da eficiência conforme o aumento } \\
\text { da população. Não houve confirmação de } \\
\text { relação positiva entre aumento da eficiência e } \\
\text { montante de recursos investidos. }\end{array}$ \\
\hline $\begin{array}{l}\text { Moraes, } \\
\text { Polizel e } \\
\text { Crozatti } \\
(2017)\end{array}$ & $\begin{array}{l}\text { Analisar a eficiência dos } \\
\text { municípios paulistas em } \\
\text { relação aos gastos públicos } \\
\text { realizados na subfunção } \\
\text { Educação Fundamental no } \\
\text { ano de } 2013 .\end{array}$ & $\begin{array}{l}585 \text { municípios } \\
\text { nos anos iniciais } \\
\text { e } 251 \text { nos anos } \\
\text { finais/2013 }\end{array}$ & $\begin{array}{l}\text { Inputs: gasto aluno; alunos } \\
\text { por turma e inverso da taxa } \\
\text { de reprovação. Output: } \\
\text { IDEB }\end{array}$ & $\begin{array}{l}\text { Nos anos iniciais, os municípios de pequeno } \\
\text { e grande porte são mais eficientes, enquanto } \\
\text { nos anos finais, os municípios de médio porte } \\
\text { se destacam. Constata-se, também, que nos } \\
\text { anos inicias há relação entre os investimentos } \\
\text { e os resultados, ao passo que nos anos finais } \\
\text { esta correlação é menor. }\end{array}$ \\
\hline $\begin{array}{l}\text { Rocha et al. } \\
\text { (2013); }\end{array}$ & $\begin{array}{l}\text { Avaliar se os recursos que } \\
\text { os municípios destinam à } \\
\text { educação são suficientes } \\
\text { para atingir as metas fixadas } \\
\text { para o IDEB em } 2021 .\end{array}$ & $\begin{array}{l}4.921 \text { municípios } \\
\text { brasileiros/2010 e } \\
2021\end{array}$ & $\begin{array}{l}\text { Inputs: gastos por alunos, } \\
\text { escolaridade da mãe. Output: } \\
\text { IDEB. }\end{array}$ & $\begin{array}{l}\text { O desperdício de recursos é expressivo, } \\
\text { representa } 40,1 \% \text { do total dos gastos } \\
\text { realizados e esse é muito maior do que o } \\
\text { gasto mínimo necessário para atingir as metas. } \\
\text { Mesmo quando são feitas simulações a partir } \\
\text { do estabelecimento de metas mais duras, } \\
\text { fica claro que a restrição não é a escassez de } \\
\text { recursos. }\end{array}$ \\
\hline $\begin{array}{l}\text { Rosano-Peña, } \\
\text { Albuquerque } \\
\text { e Márcio } \\
\text { (2012) }\end{array}$ & $\begin{array}{l}\text { Avaliar a eficiência dos } \\
\text { gastos públicos em } \\
\text { educação nos municípios } \\
\text { goianos }\end{array}$ & $\begin{array}{l}246 \text { municípios } \\
\text { goianos } / 2005 \text { a } \\
2009\end{array}$ & $\begin{array}{l}\text { Inputs: gastos com recursos } \\
\text { humanos; despesas correntes } \\
\text { e investimentos. Outputs: } \\
\text { taxa de aprovação e notas } \\
\text { em Língua Portuguesa e } \\
\text { matemática } 4^{\circ} \text { e } 8^{\circ} \text { séries e } \\
\text { números de matrículas. } \\
\end{array}$ & $\begin{array}{l}\text { Há uma correlação positiva entre os recursos } \\
\text { disponibilizados e os resultados educacionais, } \\
\text { mas isso não ocorre quando existem } \\
\text { evidências de ineficiência. A maior alocação } \\
\text { de insumos não garante melhores resultados } \\
\text { se antes não solucionar a ineficiência das } \\
\text { unidades educacionais. }\end{array}$ \\
\hline $\begin{array}{l}\text { Savian e } \\
\text { Bezerra } \\
(2013)\end{array}$ & $\begin{array}{l}\text { Avaliar a eficiência dos } \\
\text { gastos públicos com a } \\
\text { educação nas séries iniciais } \\
\text { do Ensino Fundamental } \\
\text { nos municípios do Estado } \\
\text { do Paraná. }\end{array}$ & $\begin{array}{l}381 \text { municípios } \\
\text { do estado do } \\
\text { Paraná/2005 a } 2009\end{array}$ & $\begin{array}{l}\text { Inputs: gasto por aluno; } \\
\text { número de escolas; relação } \\
\text { aluno/professor e PIB per } \\
\text { capita municipal. Output: } \\
\text { IDEB. }\end{array}$ & $\begin{array}{l}\text { A maioria dos municípios paranaenses foi } \\
\text { considerada ineficiente. Entre os anos de } \\
2005 \text { e } 2009 \text {, existiu uma redução do número } \\
\text { de municípios eficientes. }\end{array}$ \\
\hline $\begin{array}{l}\text { Schuster } \\
\text { e Zonatto } \\
(2017)\end{array}$ & $\begin{array}{l}\text { Avaliar a eficiência dos } \\
\text { gastos públicos com a } \\
\text { educação nas séries iniciais } \\
\text { do Ensino Fundamental. }\end{array}$ & $\begin{array}{l}260 \text { municípios } \\
\text { brasileiros; os dez } \\
\text { maiores de cada } \\
\text { Estado/2013. }\end{array}$ & $\begin{array}{l}\text { Input: gastos no Ensino } \\
\text { Fundamental; gasto médio } \\
\text { por aluno; IDHM na } \\
\text { dimensão e renda. Output: } \\
\text { IDEB (Séries iniciais }-1^{\mathrm{a}} \\
\text { a } 4^{\mathrm{a}} \text { ). } \\
\end{array}$ & $\begin{array}{l}\text { Os municípios mais eficientes são } \\
\text { relativamente pequenos. Os municípios } \\
\text { com maior custo por aluno matriculado } \\
\text { e localizados em regiões com maior } \\
\text { desenvolvimento econômico mostraram se } \\
\text { menos eficientes. }\end{array}$ \\
\hline $\begin{array}{l}\text { Silva e } \\
\text { Almeida } \\
(2012)\end{array}$ & $\begin{array}{l}\text { Mensurar a eficiência dos } \\
\text { municípios e relacioná-la } \\
\text { com os indicadores da } \\
\text { avaliação educacional. }\end{array}$ & $\begin{array}{l}167 \text { municípios do } \\
\text { estado do RN, em } \\
2005 .\end{array}$ & $\begin{array}{l}\text { Input: recursos do } \\
\text { FUNDEF. Outputs: alunos } \\
\text { matriculados; número de } \\
\text { professores, escolas e salas } \\
\text { de aula. }\end{array}$ & $\begin{array}{l}\text { O município mais ineficiente, embora } \\
\text { recebesse mais recursos do FUNDEF, } \\
\text { apresentou menor número de escolas, de } \\
\text { salas de aula, de alunos matriculados e de } \\
\text { professores contratados do que o mais } \\
\text { eficiente. O município mais ineficiente } \\
\text { apresentou os mais altos níveis de reprovação } \\
\text { e abandono de alunos. }\end{array}$ \\
\hline
\end{tabular}




\begin{tabular}{|c|c|c|c|c|}
\hline $\begin{array}{l}\text { Silva et al. } \\
\text { (2012) }\end{array}$ & $\begin{array}{l}\text { Avaliar a eficiência na } \\
\text { alocação dos recursos } \\
\text { destinados à educação, } \\
\text { saúde e habitação. }\end{array}$ & $\begin{array}{l}\text { Municípios de MG } \\
\text { em } 2004 .\end{array}$ & $\begin{array}{l}\text { Inputs: gastos per capita } \\
\text { com educação e cultura e } \\
\text { PIB per capita. Outputs: } \\
\text { taxa de atendimento das } \\
\text { crianças de } 4 \text { a } 6 \text { anos; taxa } \\
\text { de atendimento das crianças } \\
\text { e taxa de atendimento de } \\
\text { adolescentes }\end{array}$ & $\begin{array}{l}\text { Para a área de Educação e Cultura, com } \\
\text { base nos critérios estabelecidos, } 17,33 \% \text { dos } \\
\text { municípios analisados apresentaram baixos } \\
\text { escores de eficiência, } 65,34 \% \text { escores médios } \\
\text { e } 17,33 \% \text { escores altos. }\end{array}$ \\
\hline $\begin{array}{l}\text { Silva et al. } \\
\text { (2015) }\end{array}$ & $\begin{array}{l}\text { Avaliar se os municípios } \\
\text { foram eficientes na } \\
\text { gestão dos recursos, } \\
\text { provocando mudanças, ou } \\
\text { se permaneceram na inércia } \\
\text { social. }\end{array}$ & $\begin{array}{l}\text { Municípios de SP, } \\
\text { RJ e de BH/2005 a } \\
2011 .\end{array}$ & $\begin{array}{l}\text { Inputs: gastos na educação } \\
\text { per capita; número de } \\
\text { docentes; escolas e relação } \\
\text { de docentes por alunos. } \\
\text { Output: IDEB da } 4^{\mathrm{a}} \text { e } 8^{\mathrm{a}} \\
\text { séries. }\end{array}$ & $\begin{array}{l}5 \% \text { dos municípios são tecnicamente } \\
\text { eficientes, } 14 \% \text { são classificados } \\
\text { com ineficiência fraca, a maioria dos } \\
\text { municípios, } 65 \% \text {, estão classificados como } \\
\text { moderadamente ineficientes e } 16 \% \text { são } \\
\text { fortemente ineficientes. }\end{array}$ \\
\hline $\begin{array}{l}\text { Silva Filho et } \\
\text { al. (2016) }\end{array}$ & $\begin{array}{l}\text { Avaliar a eficiência na } \\
\text { alocação dos gastos } \\
\text { públicos com educação } \\
\text { nos Colégios Militares do } \\
\text { Exército } \\
\end{array}$ & $\begin{array}{l}12 \text { Colégios } \\
\text { Militares do } \\
\text { Brasil/2009 e } 2011\end{array}$ & $\begin{array}{l}\text { Inputs: gastos com } \\
\text { educação; número de alunos } \\
\text { matriculados e professores. } \\
\text { Output: IDEB da } 8^{\circ} \text { série. }\end{array}$ & $\begin{array}{l}\text { Os colégios que tiveram maior alocação de } \\
\text { recursos, não necessariamente, apresentaram- } \\
\text { se eficientes, indicando a necessidade de uma } \\
\text { melhor gestão dos recursos por parte dos } \\
\text { gestores. }\end{array}$ \\
\hline $\begin{array}{l}\text { Silva, Souza } \\
\text { e Araújo } \\
(2013)\end{array}$ & $\begin{array}{l}\text { Analisar a eficiência dos } \\
\text { gastos públicos com o } \\
\text { Ensino Fundamental nas } \\
\text { capitais brasileiras. }\end{array}$ & $\begin{array}{l}26 \text { capitais } \\
\text { estaduais/2007 e } \\
2009 .\end{array}$ & $\begin{array}{l}\text { Input: gastos com educação } \\
\text { fundamental. Outputs: } \\
\text { números de alunos } \\
\text { matriculados, professores e } \\
\text { escolas. }\end{array}$ & $\begin{array}{l}\text { Parece que a eficiência não possui relação } \\
\text { com a qualidade de ensino, pois os municípios } \\
\text { com maiores IDEBs não foram eficientes e os } \\
\text { municípios eficientes não cunharam um bom } \\
\text { desempenho. }\end{array}$ \\
\hline $\begin{array}{l}\text { Sousa et al. } \\
\text { (2016) }\end{array}$ & $\begin{array}{l}\text { Avaliar a eficiência e a } \\
\text { eficácia na utilização de } \\
\text { recursos públicos aplicados } \\
\text { no Ensino Fundamental } \\
\text { dos municípios capixabas. }\end{array}$ & $\begin{array}{l}58 \text { municípios do } \\
\text { estado de Espírito } \\
\text { Santo/2013. }\end{array}$ & $\begin{array}{l}\text { Inputs: gastos liquidados, } \\
\text { gasto médio por aluno; } \\
\text { IDHM educação e renda. } \\
\text { Output: IDEB. }\end{array}$ & $\begin{array}{l}\text { Os municípios eficientes apresentaram gastos } \\
\text { com Ensino Fundamental e a quantidade de } \\
\text { alunos matriculados inferiores à média da } \\
\text { amostra. Há indícios de um relacionamento } \\
\text { estatisticamente significante entre o IDHM } \\
\text { educação, a eficiência e o alcance da meta do } \\
\text { IDEB. }\end{array}$ \\
\hline $\begin{array}{l}\text { Souza e } \\
\text { Rutalira } \\
(2016)\end{array}$ & $\begin{array}{l}\text { Estimar a eficiência técnica } \\
\text { dos } 27 \text { estados brasileiros } \\
\text { no que se refere aos gastos } \\
\text { públicos em educação de } \\
\text { nível fundamental. }\end{array}$ & $\begin{array}{l}\text { Estados } \\
\text { brasileiros/2011 e } \\
2013 .\end{array}$ & $\begin{array}{l}\text { Inputs: relação aluno/ } \\
\text { professor; Fundeb/aluno; } \\
\text { aluno/escola; laboratório } \\
\text { de informática/escola e } \\
\text { biblioteca/escola. Outputs: } \\
\text { IDEB's dos estados. }\end{array}$ & $\begin{array}{l}\text { Houve avanço nos índices de eficiência entre } \\
\text { o ano de } 2011 \text { e 2013. Estados que foram } \\
\text { ineficientes estão localizados nas regiões norte } \\
\text { e nordeste. Uma maior alocação de recursos } \\
\text { não significa melhores resultados. Um maior } \\
\text { volume de recursos destinados a DMU's } \\
\text { ineficientes resultará em maiores desperdícios } \\
\text { e, naturalmente a eficiência global tende a } \\
\text { regredir. }\end{array}$ \\
\hline $\begin{array}{l}\text { Souza et al. } \\
(2012)\end{array}$ & $\begin{array}{l}\text { Analisar a eficiência dos } \\
\text { gastos públicos com ensino } \\
\text { fundamental nos estados } \\
\text { brasileiros. }\end{array}$ & \begin{tabular}{|l|}
23 Estados \\
Brasileiros/2009
\end{tabular} & $\begin{array}{l}\text { Input: gastos com Ensino } \\
\text { Fundamental. Output: IDEB } \\
\text { do } 5^{\circ} \text { ao } 9^{\circ} \text { ano. }\end{array}$ & $\begin{array}{l}\text { A eficiência não teve relação com a qualidade } \\
\text { do ensino. Foi possível perceber que } \\
\text { quando os escores de eficiência dos estados } \\
\text { aumentam não são acompanhados de um } \\
\text { crescimento no desempenho dos alunos no } \\
\text { IDEB. }\end{array}$ \\
\hline $\begin{array}{l}\text { Trompieri } \\
\text { Neto et al. } \\
(2009)\end{array}$ & $\begin{array}{l}\text { Avaliar a qualidade dos } \\
\text { gastos públicos municipais } \\
\text { do Estado do Ceará em } \\
\text { educação e saúde. }\end{array}$ & $\begin{array}{l}173 \text { municípios } \\
\text { cearenses/2004 }\end{array}$ & $\begin{array}{l}\text { Inputs: gastos com educação } \\
\text { por aluno matriculado. } \\
\text { Output: produtos (professor, } \\
\text { salas de aula e alunos) e } \\
\text { resultados (notas dos alunos } \\
\text { no SPAECE, Estado do } \\
\text { Ceará). }\end{array}$ & $\begin{array}{l}\text { Os municípios eficientes em transformar } \\
\text { insumo em produto, não são eficientes na } \\
\text { transformação de insumo em resultado, e } \\
\text { vice-versa. Isso retrata a subutilização dos } \\
\text { produtos e o mau planejamento na definição } \\
\text { dos produtos necessários. O IDH, ou seja, } \\
\text { condições sócio econômicas, contribui mais } \\
\text { para o aumento da eficiência do que o gasto } \\
\text { per capita. }\end{array}$ \\
\hline $\begin{array}{l}\text { Wilbet e } \\
\text { D'Abreu } \\
(2013)\end{array}$ & $\begin{array}{l}\text { Avaliar a eficiência dos } \\
\text { gastos públicos com } \\
\text { Educação Fundamental. }\end{array}$ & $\begin{array}{l}57 \text { municípios de } \\
\text { Alagoas/2007 a } \\
2011 .\end{array}$ & $\begin{array}{l}\text { Inputs: gasto empenhado } \\
\text { com educação per capita; } \\
\text { número de habitantes e de } \\
\text { alunos e PIB per capita. } \\
\left.\text { Output: IDEB ( } 4^{a} \text { série }\right)\end{array}$ & $\begin{array}{l}\text { Os municípios eficientes foram os que } \\
\text { tiveram piores condições, em riqueza média } \\
\text { e nível educacional, como também gastaram } \\
\text { pouco por aluno matriculado. Os menos } \\
\text { eficientes foram aqueles com a melhor } \\
\text { condição de partida em termos de PIB per } \\
\text { capita e que apresentaram elevados gastos } \\
\text { por aluno e ainda alcançaram os piores } \\
\text { desempenhos no IDEB. }\end{array}$ \\
\hline
\end{tabular}




\begin{tabular}{|l|l|l|l|l|}
\hline $\begin{array}{l}\text { Zoghbi et al. } \\
(2011)\end{array}$ & $\begin{array}{l}\text { Avaliar a eficiência relativa } \\
\text { dos municípios paulistas no } \\
\text { que diz respeito aos gastos } \\
\text { em Educação Fundamental. }\end{array}$ & $\begin{array}{l}457 \text { municípios de } \\
\text { São Paulo/2005 }\end{array}$ & $\begin{array}{l}\text { Inputs: gasto por aluno. } \\
\text { Outputs: variável distorção } \\
\text { idade-série; taxa de } \\
\text { aprovação; proficiência } \\
\text { da Prova Brasil, IDEB e } \\
\text { indicador médio, }\end{array}$ & $\begin{array}{l}\text { O grupo mais populoso, com mais de 100 } \\
\text { mil habitantes, foi o mais eficiente e o menos } \\
\text { populoso, com até 5 mil habitantes, foi o } \\
\text { menos eficiente. }\end{array}$ \\
\hline
\end{tabular}

Fonte: Desenvolvido com base nos autores.

\section{Apresentação e análise dos resultados}

Nesta seção apresenta-se as análises da avaliação da eficiência dos gastos públicos no Ensino Fundamental nos municípios do Estado do Paraná no ano de 2015. Para tal, buscou-se: apresentar estatísticas descritivas das variáveis que compõe o modelo; apresentar as estatísticas descritivas que tratam das eficiências das DMU's; verificar o relacionamento entre as variáveis analisadas; como também procurou-se identificar e apontar as diferenças entre os desempenhos dos municípios.

\section{Estatísticas descritivas das variáveis que compõe o modelo}

A Tabela 01 apresenta algumas estatísticas descritivas dos inputs investimentos por aluno, número de docentes por aluno e número de escolas por 100 alunos e o output IDEB.

Tabela 1. Estatísticas descritivas das variáveis que compõe o modelo

\begin{tabular}{lcccc}
\hline Estatística descritiva & $\begin{array}{c}\text { Investimento } \\
\text { por aluno }\end{array}$ & $\begin{array}{c}\text { Número de } \\
\text { docentes por } \\
\text { aluno }\end{array}$ & $\begin{array}{c}\text { Número de } \\
\text { escolas por 100 } \\
\text { alunos }\end{array}$ & IDEB \\
\hline Média & $5.684,74$ & 0,1576 & 0,6875 & 5,8887 \\
Mediana & $5.600,17$ & 0,1519 & 0,6263 & 5,9000 \\
Desvio padrão & $1.596,04$ & 0,0549 & 0,3159 & 0,6388 \\
Coeficiente de variação & 0,2808 & 0,3480 & 0,4596 & 0,1085 \\
Menor & $1.664,38$ & 0,0416 & 0,2451 & 3,8000 \\
Maior & $12.406,59$ & 0,4568 & 3,0189 & 8,1000 \\
\hline
\end{tabular}

Fonte: Compilação dos resultados coletados pelos autores, 2018.

Primeiramente, quanto ao resultado do Índice de Desenvolvimento da Educação Básica, IDEB, os municípios alcançaram uma média de cerca de 5,89, com desvio padrão de 0,64 , que indica a menor dispersão de dados das variáveis estudadas. $\mathrm{Na}$ figura 01 pode-se visualizar as notas alcançadas pelos municípios estudados. A escala foi desenvolvida conforme o critério de quebras naturais (Jenks), que identificam pontos de quebra que melhor agrupem valores similares e maximizem a diferença entre as classes, no software QGis,. 
Figura 1. Distribuição espacial dos Índices de Desenvolvimento da Educação Básica dos Municípios Paranaenses

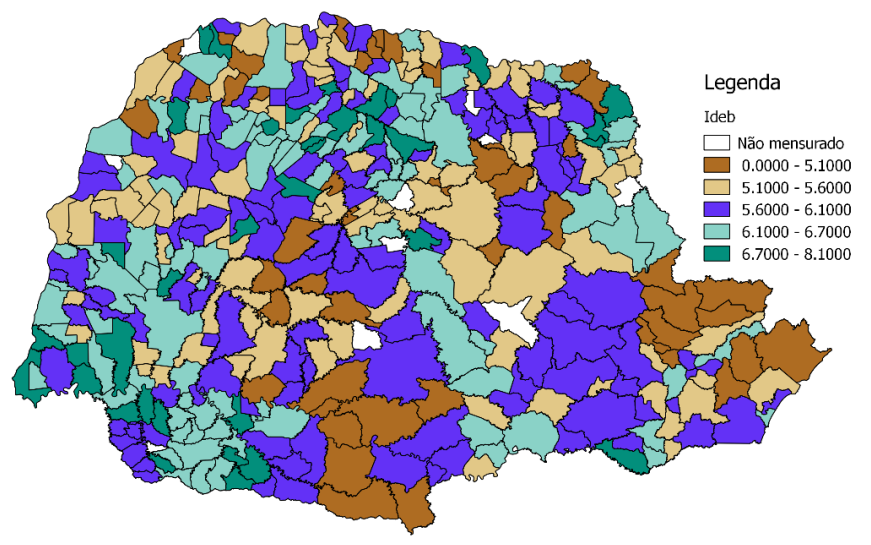

Fonte: Compilação dos resultados coletados pelos autores, 2018.

Deve-se reconhecer que a meta do IDEB é importante, uma vez que o mesmo é um condutor de política pública na educação, como também uma ferramenta para acompanhamento da qualidade do Plano de Desenvolvimento da Educação para a educação básica, que tem estabelecido, como meta, que em 2022 o resultado nacional seja 6,0 , o qual equivale a um sistema educacional de qualidade comparável a dos países desenvolvidos (INEP, 2018). Em média, pode-se afirmar que os municípios paranaenses foram superiores a meta estabelecida para o ano de 2015, a qual era de 5,49. Todavia, quanto ao alcance da meta, 71 municípios, ou seja, cerca de $18 \%$, ficaram abaixo do esperado.

É importante também destacar os cinco municípios que obtiveram as maiores notas, que foram: Atalaia $(8,1)$; Serranópolis do Iguaçu $(8,1)$; Sertaneja $(7,8)$; Céu Azul $(7,4)$; e Nova Londrina $(7,4)$. Já os municípios Nossa Senhora das Graças $(3,8)$, Tunas do Paraná $(4,4)$ e Antonina, Cerro Azul, Laranjal, Lupionópolis, Mato Rico, Pinhão, Porto Rico, São Jerônimo da Serra e Sapopema, todos com um índice de 4,7, obtiveram os menores scores.

Já quanto ao input investimento por aluno, a média foi de $\mathrm{R} \$ 5.685,00$ por aluno, com desvio padrão de cerca de $R \$ 1.600,00$, dado um coeficiente de variação de 0,28 . Os municípios que mais aportaram recursos na educação foram: Porto Barreiro (R\$ 12.406,59); Barra do Jacaré ( $\mathrm{R}$ \$ 11.282,42); Santa Inês (R \$ 10.826,76); Miraselva (R\$ 10.578,52); Nova Laranjeiras (R\$
10.266,72); e Manfrinópolis ( $\mathrm{R} \$$ 10.204,98). Em contrapartida os municípios que menos investiram foram: Tijucas do Sul (R\$ 1.664,38); Sarandi (R\$ 2.089,87); Moreira Sales (R $2.151,93)$; Santa Isabel do Ivaí $(\mathrm{R} \$ 2.339,08)$; Florestópolis $(\mathrm{R} \$ 2.474,76)$; e São Tomé $(\mathrm{R} \$ 2.531,70)$.

A média de docentes por aluno nos municípios estudados foi de 0,1576, o que indica uma quantidade de cerca de 6,34 alunos por professor, com um desvio padrão de 0,0549 e coeficiente de variação de 0,3480 . Vale mencionar que um índice menor indica uma quantidade maior de alunos por professor e, logicamente, um número maior indica uma quantidade menor de alunos por professor. Os municípios com a maior quantidade de alunos foram: Carlópolis (0,0416); Tunas do Paraná (0,0490); Miraselva $(0,0491)$; e Telêmaco Borba $(0,0496)$. Os municípios com a menor quantidade de alunos por professor foram: Vitorino (0,4568); Fernandes Pinheiro (0,3739); Mercedes (0,3697); e Espigão Alto do Iguaçu (0,3620).

O input número de escolas por 100 alunos demonstra uma média 0,6875, ou seja, cerca de 145 alunos por escola, com um desvio padrão de 0,3159 e o coeficiente de variação de 0,4596. Ressalta-se que, tal como ocorre no input anterior, um índice menor indica uma quantidade maior de alunos por escola e, logicamente, um número maior indica uma quantidade menor de alunos por escola. Complementarmente, pode-se destacar a grande variabilidade desses dados, há escolas com cerca de 400 alunos, como em de Fazenda Rio Grande $(0,2451)$ Bom Sucesso $(0,2238)$ e Renascença $(0,2762)$, e outras com menos de 50 alunos, como nos municípios com Guaraqueçaba $(3,02)$, Doutor Ulysses $(2,40)$ e Santa Inês $(2,05)$.

\section{Estatísticas descritivas das eficiências}

A tabela 02 apresenta algumas estatísticas descritivas dos dados da eficiência técnica (EF) com retornos constantes de escala (CCR), rendimentos variáveis de escala (BCC), eficiência de escala (EE) e o alvo. Já a figura 02 apresenta a distribuição espacial da eficiência técnica com rendimentos variáveis de escala. 
Tabela 2 . Estatísticas descritivas da análise da eficiência

\begin{tabular}{lrrrrrr}
\hline & ET(ccr) & ET(bcc) & EE & $\begin{array}{c}\text { Alvo } \\
\text { Investimento }\end{array}$ & $\begin{array}{c}\text { Alvo } \\
\text { Docentes }\end{array}$ & $\begin{array}{c}\text { Alvo } \\
\text { Escolas }\end{array}$ \\
\hline Média & 0,5578 & 0,6079 & 0,9174 & $3.082,06$ & 0,086 & 0,351 \\
Mediana & 0,5346 & 0,5858 & 0,9348 & 740,83 & 0,026 & 0,100 \\
Desvio padrão & 0,1559 & 0,1624 & 0,0690 & 0,23 & 0,29 & 0,27 \\
Coeficiente de variação & $28 \%$ & $27 \%$ & $7,5 \%$ & $1.664,38$ & 0,04 & 0,25 \\
Menor & 0,2284 & 0,2449 & 0,6055 & $8.034,74$ & 0,14 & 1,25 \\
Maior & 1,0000 & 1,0000 & 1,0000 & $3.082,06$ & 0,086 & 0,351 \\
\hline
\end{tabular}

Fonte: Compilação dos resultados obtidos pelos autores no software R, 2018.

$\mathrm{Na}$ análise das eficiências total, técnica e de escala, não se percebeu fortes indícios de problemas quanto à eficiência de escala, visto que a mesma possui uma média alta, ou seja, uma eficiência de cerca de $92 \%$, bem como um baixo desvio padrão. Com a eficiência total (ETccr) e o produto da eficiência de escala (EE) pela eficiência técnica (ETbcc), pode-se concluir que o principal problema dos municípios está ligado à eficiência técnica, pois a mesma apresenta uma média de cerca de $61 \%$ e um alto desvio padrão. Entre os municípios eficientes, ou seja, com um índice de eficiência técnica com retornos variáveis de escala de 100\%, destacam-se: Tunas do Paraná; Sarandi; Tijucas do Sul; Telêmaco Borba; Fazenda Rio Grande; Paiçandu; Carlópolis; São Tomé; Cianorte; Japurá; Sertaneja; Atalaia; e Serranópolis do Iguaçu. Essa informação coincide com os trabalhos de Silva et al. (2012), Savian e Bezerra (2013), Diel et al.-2014, Dantas, Costa e Silva (2015), Silva et al. (2015), Lourenço et al. (2017), Monte e Leopoldino (2017), que afirmam que poucos municípios se mostraram eficientes.

Figura 2 . Distribuição Espacial das Eficiências Técnicas (ETbcc) dos Municípios Paranaenses

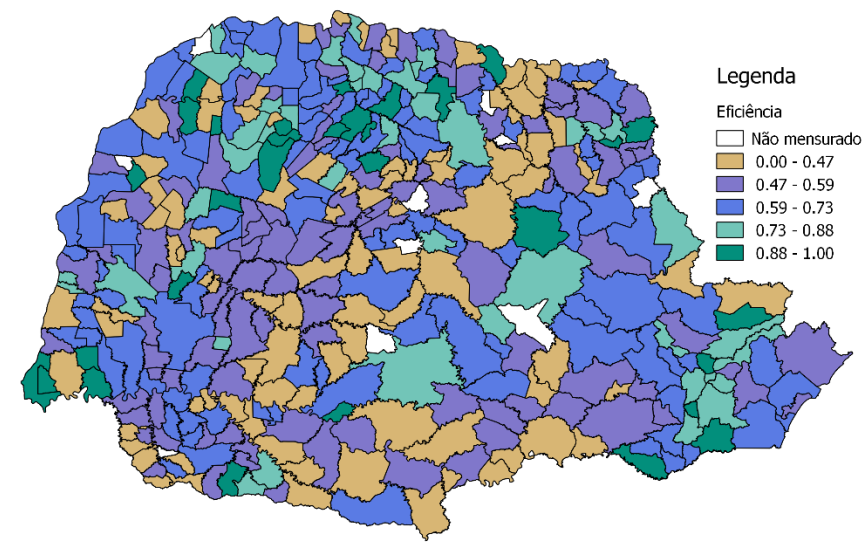

Fonte: Compilação dos resultados coletados pelos autores, 2018.

Através da tabela 2 constatou-se que os municípios, em média, devem investir por aluno $\mathrm{R} \$ 3.082,06$, possuir um número de docentes por aluno de cerca de 0,09, que significa cerca de 11 alunos por docente e cerca de 0,35 escolas por 100 alunos, ou seja, uma escola para cerca de 286 alunos. Tais dados correspondem aos alvos obtidos pela abordagem utilizada com orientação a inputs. Porém, em contrapartida, pode-se dizer que o resultado obtido se apresenta em um patamar muito aquém do eficiente verificado pelo modelo, uma vez que se são suficientes menos inputs para se alcançar os resultados obtidos, confirma-se a ineficiência técnica demonstrada.

Os resultados apresentados vão ao encontro dos achados de Bohrer, Comunelo, Godarth (2013), que indicam que os municípios que possuem os maiores custos por aluno não figuram nas primeiras posições da eficiência na gestão dos gastos com educação; de Dantas, Costa e Silva (2015) e Savian e Bezerra (2013), que identificaram, nos Estados do Rio Grande do Norte e Paraná, poucos municípios eficientes, indicando que os recursos públicos em educação fundamental são mal alocados; 


\section{Análise de correlação das variáveis}

Para um melhor entendimento dos resultados, desenvolveu-se uma análise de correlação das variáveis. Como uma variável que compõe o modelo não apresentou normalidade, optou-se por utilizar teste não paramétrico, ou seja, procedimento estatístico que trabalha com a categorização dos dados, denominado teste de Spearman (FIELD, 2009; DANCEY e REIDY, 2013).

Tabela 3 . Correlações das variáveis

\begin{tabular}{lcccc}
\hline & Investimentos & Docentes & Escolas & IDEB \\
\hline Docentes & $0,214^{* *}$ & & & \\
Escolas & $0,387^{* *}$ & 0,034 & & \\
IDEB & $-0,103^{*}$ & $0,152^{* *}$ & $-0,155^{* *}$ & \\
Eficiência & $-0,644^{* *}$ & $-0,406^{* *}$ & $-0,715^{* *}$ & $0,289^{* *}$ \\
(bcc) & & & \\
\hline
\end{tabular}

Fonte: Compilação dos resultados obtidos pelos autores no software SPSS, 2018.

Nota: **A correlação é significativa no nível 0,01. * A correlação é significativa no nível 0,05 .

A variável Investimento possui uma correlação significativa negativa moderada com a variável Eficiência ( $\mathrm{n}=389 ; p=-0,644 ; \mathrm{p}<0,01)$; já com as variáveis Docentes $(\mathrm{n}=389 ; p=0,214 ; \mathrm{p}<0,01)$ e Escolas ( $\mathrm{n}=389 ; p=0,387 ; \mathrm{p}<0,01)$, obteve-se uma correlação significativa positiva fraca e, em destaque, uma correlação significativa negativa fraca com o índice do $\operatorname{IDEB}(\mathrm{n}=389 ; p=-0,103 ; \mathrm{p}<0,05)$. A variável Docentes não encontrou uma associação significativa $(\mathrm{p}<0,05)$ com Escolas, mas um relacionamento significativo negativo moderado com a variável Eficiência ( $\mathrm{n}=389$; $p=-0,406 ; \mathrm{p}<0,01)$ e uma correlação positiva negativa fraca com a variável IDEB ( $\mathrm{n}=389 ; p=0,152 ; \mathrm{p}<0,01)$. A variável Escola apresenta correlação negativamente forte com Eficiência $(\mathrm{n}=389 ; p=-0,715 ; \mathrm{p}<0,01)$ e fracamente com IDEB ( $\mathrm{n}=389 ; p=-0,155 ; \mathrm{p}<0,01)$. Por fim, a variável IDEB tem uma relação positiva fraca com a Eficiência ( $\mathrm{n}=389 ; p=0,289 ; \mathrm{p}<0,01)$.

Assim, diferente de Moraes, Polizel e Crozatti (2017), os quais defendem que apreenderam que nos anos inicias existe uma relação entre os investimentos e os resultados, a presente pesquisa, por meio das correlações, percebeu um relacionamento negativo fraco entre investimentos e escolas e positivo com docentes; já a eficiência possui um relacionamento negativo forte com investimentos e escolas e negativo fraco com docentes, como também um relacionamento positivo fraco com o IDEB. Assim, cabe mencionar os achados de Souza et al. (2012); Silva, Souza e Araújo (2013); e Monte e Leopoldino (2017), os quais enfatizam que não se confirma a relação positiva entre aumento da eficiência e montante de recursos investidos.

\section{Análise de agrupamento dos municípios}

Desenvolveu-se também uma análise de agrupamentos, ou como é conhecido, análise de clusters, que é um método empírico para realizar a classificação de objetos, nesse caso, com o objetivo de simplificação e exploração dos dados (HAIR, 2009). Para essa análise, utilizou-se as variáveis investimentos por alunos, docentes por alunos, escolas por alunos, IDEB e o índice de eficiência técnica pura (ETbcc).

A análise de agrupamentos não é uma técnica de inferência estatística através da qual os parâmetros de uma amostra são avaliados como possivelmente representativos de uma população, mas sim busca quantificar características estruturais de um conjunto de observações. Como ela tem propriedades matemáticas e não estatísticas, não se torna importante as exigências de normalidade, homocedasticidade e linearidade. Entretanto, deve-se preocupar com a representatividade da amostra e a multicolinearidade. (HAIR, 2005). Assim, quanto à amostra, é evidente que a presente pesquisa é representativa, pois possui dados de 389 municípios de uma população de 399 no Paraná. Com isso, é possível afirmar que há dados representativos e que as observações atípicas pertencem realmente à população em estudo. Já quanto à multicolinearidade, que é a representação dos altos níveis de correlação entre as variáveis independentes, na análise de agrupamentos, as variáveis com essa característica são implicitamente ponderadas com maior peso. Foi desenvolvido testes para a análise da multicolinearidade, sugerida por Field (2009), pelos quais os valores de FIV estão todos abaixo de 10 e as tolerâncias todas acima de 0,20 , concluindo-se que os dados não apresentam significativos níveis de multicolinearidade.

O delineamento da análise de agrupamentos seguiu os procedimentos indicados por Hair (2009). Primeiramente, foi analisado a presença de dados atípicos entre aqueles coletados e não se encontrou 
um forte caso necessário a ser eliminado da base de dados. Além, dado que o conjunto de dados trabalhados ser considerado métricos, a distância euclidiana quadrática foi utilizada como medida de semelhança e o procedimento hierárquico, por meio do método Ward foi escolhido para minimizar as diferenças internas de grupos e evitar problemas de encadeamento das ligações. Além disso, desenvolveu-se uma padronização das variáveis por meio do score $Z$, haja vista as diferenças de medidas entre as variáveis estudadas.

Quanto ao número de grupos, visto que o interesse foi em identificar perfis que pudessem desenvolver análises e estratégias de ações, acredita-se que algo entre dois a seis agregados seja o adequado. Para uma seleção mais acurada, utilizou-se do coeficiente de aglomeração, o qual é utilizado para uso em uma regra de parada e tem se apresentado como um algoritmo preciso, como indica Hair (2009). Ao final, foram encontrados quatro agrupamentos: o grupo 01, que agrupou 97 municípios; o segundo grupo, com 142; terceiro grupo, 12; e o quarto grupo, 138.

Na tabela 04, apresenta-se o perfil de cada grupo de municípios com as respectivas médias dos inputs e outputs que formam o modelo.

Tabela 4 . Estatísticas das variáveis que formam o modelo por grupos

\begin{tabular}{|c|l|c|c|c|c|}
\hline Grupo & \multicolumn{1}{|c|}{ Estatística descritiva } & Investimentos & Docentes & Escolas & IDEB \\
\hline \multirow{4}{*}{1} & Média & $6.044,09$ & 0,1355 & 0,8572 & 5,47 \\
\cline { 2 - 6 } & Mediana & $6.103,51$ & 0,1409 & 0,7764 & 5,50 \\
\cline { 2 - 5 } & Desvio padrão & $1.086,61$ & 0,0351 & 0,2633 & 0,51 \\
\cline { 2 - 6 } & Coeficiente de variação & 0,1780 & 0,2491 & 0,3391 & 0,0927 \\
\hline \multirow{4}{*}{2} & Média & $4.485,19$ & 0,1332 & 0,4813 & 5,88 \\
\cline { 2 - 6 } & Mediana & $4.512,14$ & 0,1315 & 0,4589 & 5,90 \\
\cline { 2 - 6 } & Desvio padrão & $1.018,67$ & 0,0401 & 0,1278 & 0,59 \\
\cline { 2 - 6 } & Coeficiente de variação & 0,2258 & 0,3049 & 0,2785 & 0,1000 \\
\hline \multirow{4}{*}{3} & Média & $9.011,33$ & 0,1500 & 1,6654 & 5,25 \\
\cline { 2 - 6 } & Mediana & $9.718,63$ & 0,1397 & 1,5429 & 5,15 \\
\cline { 2 - 6 } & Desvio padrão & $2.318,52$ & 0,0556 & 0,6315 & 0,50 \\
\cline { 2 - 6 } & Coeficiente de variação & 0,2386 & 0,3980 & 0,4093 & 0,0971 \\
\hline \multirow{4}{*}{4} & Média & $6.377,20$ & 0,1990 & 0,6953 & 6,24 \\
\cline { 2 - 6 } & Mediana & $6.176,81$ & 0,1903 & 0,6842 & 6,15 \\
\cline { 2 - 6 } & Desvio padrão & $1.360,96$ & 0,0554 & 0,1923 & 0,57 \\
\cline { 2 - 5 } & Coeficiente de variação & 0,2203 & 0,2911 & 0,2811 & 0,0927 \\
\hline
\end{tabular}

Fonte: Compilação dos resultados obtidos pelos autores no software SPSS, 2018.

Negativamente pode-se dar destaque ao grupo 3, que, apesar de ser pequeno, com apenas 12 municípios, possui o maior investimento por aluno, a segunda maior quantidade de docentes por alunos, a maior quantidade de escolas e a pior média de IDEB. O grupo 2 possui o segundo melhor IDEB e o menor investimento por aluno, como também o menor número de docentes por aluno e escolas por aluno. Destaca-se o grupo 4, o qual apresentou o melhor IDEB, são os municípios que possuem a maior quantidade de docentes por aluno, cerca de um docente para cada cinco alunos.

A tabela 05 traz as médias das eficiências e alvos. No que tange à eficiência técnica, deve-se mencionar o índice de eficiência superior do grupo 2 (média de 75\%), sendo que 10 municípios caracterizados como eficientes fazem parte deste grupo. Negativamente, destaca-se o grupo 3, por possuir a menor média de eficiência. 
Figura 3 . Distribuição Espacial dos Grupos dos Municípios Paranaenses

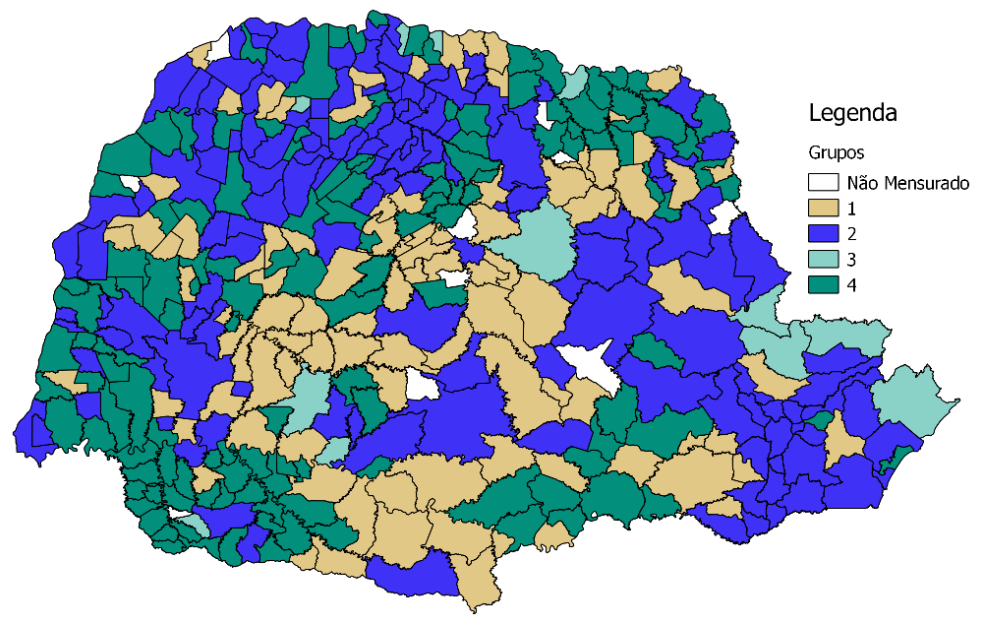

Fonte: Compilação dos resultados coletados pelos autores, 2018.

O grupo 1 e o grupo 4 possuem médias de eficiência técnica (ET/bcc) similares, cerca de 52\% e 54\%, respectivamente. Parece que no caso desses dois grupos existe uma relação mais linear do IDEB com os inputs, ou seja, o grupo 4 teve um resultado maior, pois aportou mais recursos, enquanto o grupo 1 aportou menos e teve uma eficiência menor, logo, as eficiências, dado a relação output/input, resultam uma similaridade. Entretanto, esse argumento se torna inválido se considerarmos os inputs e outputs dos grupos 3 e 2.

Tabela 5 . Médias das eficiências obtidas pelos grupos

\begin{tabular}{|c|l|c|c|c|c|c|c|}
\hline Grupo & Estatística descritiva & ET(ccr) & ET(bcc) & EE & $\begin{array}{c}\text { Alvo } \\
\text { Investimento }\end{array}$ & $\begin{array}{c}\text { Alvo } \\
\text { Docentes }\end{array}$ & $\begin{array}{c}\text { Alvo } \\
\text { Escolas }\end{array}$ \\
\hline \multirow{4}{*}{1} & Média & 0,4647 & 0,5237 & 0,8856 & $3.070,08$ & 0,0687 & 0,4163 \\
\cline { 2 - 8 } & Mediana & 0,4573 & 0,5175 & 0,8970 & 2889,58 & 0,070 & 0,4130 \\
\cline { 2 - 8 } & Desvio padrão & 0,0941 & 0,0909 & 0,0715 & 611,02 & 0,0136 & 0,083 \\
\cline { 2 - 8 } & Coef. de variação & 0,2025 & 0,1736 & 0,0807 & 0,1990 & 0,1980 & 0,1994 \\
\hline \multirow{3}{*}{2} & Média & 0,6959 & 0,7534 & 0,9225 & $3.258,10$ & 0,0956 & 0,3544 \\
\cline { 2 - 8 } & Mediana & 0,6747 & 0,7115 & 0,9366 & $3.255,28$ & 0,0960 & 0,3240 \\
\cline { 2 - 8 } & Desvio padrão & 0,1311 & 0,1252 & 0,0682 & 687,59 & 0,0259 & 0,0903 \\
\cline { 2 - 8 } & Coef. de variação & 0,1884 & 0,1662 & 0,0739 & 0,2110 & 0,2709 & 0,2548 \\
\hline \multirow{3}{*}{3} & Média & 0,3319 & 0,3941 & 0,8554 & $3.364,44$ & 0,0541 & 0,4652 \\
\cline { 2 - 8 } & Mediana & 0,3306 & 0,3950 & 0,8368 & $3.028,09$ & 0,0520 & 0,4870 \\
\cline { 2 - 8 } & Desvio padrão & 0,0746 & 0,1093 & 0,0764 & 845,29 & 0,0085 & 0,0613 \\
\cline { 2 - 8 } & Coef. de variação & 0,2248 & 0,2773 & 0,0893 & 0,2512 & 0,1571 & 0,1318 \\
\hline \multirow{3}{*}{4} & Média & 0,5008 & 0,5359 & 0,9398 & $3.311,10$ & 0,1010 & 0,3609 \\
\cline { 2 - 8 } & Mediana & 0,4860 & 0,5091 & 0,9526 & $3.084,74$ & 0,0990 & 0,3370 \\
\cline { 2 - 8 } & Desvio padrão & 0,1042 & 0,1250 & 0,0552 & 849,51 & 0,0232 & 0,1101 \\
\cline { 2 - 8 } & Coef. de variação & 0,2081 & 0,2333 & 0,0587 & 0,2566 & 0,2297 & 0,3051 \\
\hline
\end{tabular}

Fonte: Compilação dos resultados obtidos pelos autores no software SPSS, 2018.

Os resultados corroboram os achados de Diniz e Corrar (2011), Bohrer, Comunelo e Godarth (2013), Wilbet e D’Abreu (2013), Souza e Rutalira (2016), Lourenço et al. (2017) e Moraes, Polizel e Crozatti (2017), que afirmam que maiores aportes financeiros, não asseguram melhores resultados ou qualidade na educação. 


\section{Análise das diferenças entre os agrupamentos}

Para uma melhor compreensão dos resultados, buscou-se desenvolver um comparativo entre os grupos formados pela análise de clusters. Como uma variável que compõe o modelo não apresentou normalidade, optou-se por utilizar procedimentos estatísticos que trabalham com a categorização dos dados. Primeiramente, foi utilizado o teste Kuskal-Wallis, o qual analisa a presença de diferença entre vários grupos independentes (FIELD, 2009). Verificou-se, assim, diferenças significativas entre investimentos por alunos $(\mathrm{H}(3)=158,48, \mathrm{p}<0,01)$, docentes por alunos $(\mathrm{H}(3)=130,24, \mathrm{p}<0,01)$, escolas por alunos $(\mathrm{H}(3)=185,77, \mathrm{p}<0,01)$, IDEB $(\mathrm{H}(3)=97,69, \mathrm{p}<0,01)$ e eficiência técnica $(\mathrm{H}(3)=204,57, \mathrm{p}<0,01)$.

Além disso, para uma análise mais detalhada das diferenças entre os grupos, foi desenvolvida uma análise post hoc não-paramétrico. Para tal, seguiu as orientações de Field (2009), através das quais foi desenvolvido um comparativo de cada grupo por meio do teste Mann-Whitney. Contudo, para que o Erro do Tipo I não ultrapassasse o valor de 0,05; ou seja, chegar a um resultado que tem significância estatística quando na verdade ele aconteceu por acaso, utilizou-se a correção de Bonferroni. Desta forma, os efeitos foram testados a um nível de significância de 0,0083 , que é a razão da significância $(0,05)$ pelo número de comparações realizadas $(6$, ou ainda, $1 \times 2 ; 1 \times 3 ; 1 \times 4 ; 2 \times 3 ; 2 \times 4 ; 3 \times 4)$.

Tabela 6 . Resultados dos comparativos dos grupos.

\begin{tabular}{|c|c|c|c|c|c|c|}
\hline $\begin{array}{l}\text { COMPARA } \\
\text { ÇÃO ENTRE } \\
\text { GRUPOS }\end{array}$ & TESTE & INVESTIMENTOS & DOCENTES & ESCOLAS & IDEB & $\begin{array}{c}\text { Eficiência } \\
\text { (bcc) }\end{array}$ \\
\hline \multirow{4}{*}{$1 \times 2$} & U de Mann-Whitney & 1.990 & 6.413 & 886 & 4.116 & 657 \\
\hline & $\mathrm{Z}$ & $-9,33$ & $-0,90$ & $-11,43$ & $-5,29$ & $-11,87$ \\
\hline & Significância Sig. & $0,0001^{*}$ & 0,37 & $0,0001 *$ & $0,0001 *$ & $0,0001 *$ \\
\hline & $\mathrm{r}$ & $-0,47$ & $-0,05$ & $-0,58$ & $-0,27$ & $-0,60$ \\
\hline \multirow{4}{*}{$1 \times 3$} & U de Mann-Whitney & 200 & 516 & 88 & 424 & 216 \\
\hline & $\mathrm{Z}$ & $-3,70$ & $-0,64$ & $-4,78$ & $-1,53$ & $-3,54$ \\
\hline & Significância Sig. & $0,0001 *$ & 0,52 & $0,0001 *$ & 0,13 & $0,0001 *$ \\
\hline & $\mathrm{r}$ & $-0,19$ & $-0,03$ & $-0,24$ & $-0,08$ & $-0,18$ \\
\hline \multirow{4}{*}{$1 \times 4$} & U de Mann-Whitney & 5.937 & 1.950 & 4.276 & 1.978 & 6.624 \\
\hline & $\mathrm{Z}$ & $-1,47$ & $-9,25$ & $-4,71$ & $-9,20$ & $-0,13$ \\
\hline & Significância Sig. & 0,14 & $0,0001 *$ & $0,0001 *$ & $0,0001^{*}$ & 0,89 \\
\hline & $\mathrm{r}$ & $-0,07$ & $-0,47$ & $-0,24$ & $-0,47$ & $-0,01$ \\
\hline \multirow{4}{*}{$2 \times 3$} & U de Mann-Whitney & 93 & 736 & - & 345 & 6 \\
\hline & $\mathrm{Z}$ & $-5,12$ & $-0,78$ & $-5,74$ & $-3,43$ & $-5,70$ \\
\hline & Significância Sig. & $0,0001 *$ & 0,43 & $0,0001^{*}$ & $0,0001^{*}$ & $0,0001^{*}$ \\
\hline & $\mathrm{r}$ & $-0,26$ & $-0,04$ & $-0,29$ & $-0,17$ & $-0,29$ \\
\hline \multirow{4}{*}{$2 \times 4$} & U de Mann-Whitney & 2.381 & 2.865 & 3.363 & 6.656 & 1.871 \\
\hline & Z & $-10,95$ & $-10,24$ & $-9,50$ & $-4,65$ & $-11,70$ \\
\hline & Significância Sig. & $0,0001 *$ & $0,0001^{*}$ & $0,0001 *$ & $0,0001 *$ & $0,0001 *$ \\
\hline & $\mathrm{r}$ & $-0,56$ & $-0,52$ & $-0,48$ & $-0,24$ & $-0,59$ \\
\hline \multirow{4}{*}{$3 \times 4$} & U de Mann-Whitney & 308,0 & 460,0 & 32,0 & 150,0 & 319,0 \\
\hline & Z & $-3,60$ & $-2,55$ & $-5,51$ & $-4,71$ & $-3,53$ \\
\hline & Significância Sig. & $0,0001 *$ & 0,01 & $0,0001^{*}$ & $0,0001 *$ & $0,0001 *$ \\
\hline & $\mathrm{r}$ & $-0,18$ & $-0,13$ & $-0,28$ & $-0,24$ & $-0,18$ \\
\hline
\end{tabular}

Fonte: Compilação dos resultados obtidos pelos autores no software SPSS, 2018.

Nota: * diferença significativa a um nível de 0,0083

Por meio dos testes post hoc foi possível comparar as diferenças entre os grupos. Primeiramente, comparou-se os resultados do grupo $1 \mathrm{com}$ o grupo 2, percebendo-se uma diferença significativa em investimentos $(\mathrm{U}=$ 
1.900, $\mathrm{r}=-0,47)$, escolas $(\mathrm{U}=886, \mathrm{r}=-0,58)$, IDEB $(\mathrm{U}=4.116, \mathrm{r}=-0,27)$ e eficiência $(\mathrm{BCC})(\mathrm{U}=657, \mathrm{r}=$ $-0,60)$. Verificou-se, também, que não há diferenças significativas quanto aos investimentos por alunos, bem como gastos com docentes por alunos entre esses grupos $(\mathrm{U}=6.413, \mathrm{r}=-0,05)$. Em síntese, podese inferir que o grupo 2, em comparação com o grupo 1, foi mais eficiente, uma vez que teve um resultado (IDEB) melhor, utilizando menos investimentos e com melhor utilização das escolas.

No comparativo do grupo 1 com o grupo 3, percebese diferenças significativas quanto aos investimentos $(\mathrm{U}=200, \mathrm{r}=-0,19)$, escolas $(\mathrm{U}=88, \mathrm{r}=-0,24) \mathrm{e}$ eficiência $(U=216, r=-0,18)$, todavia não se constatou diferenças significativas quanto ao número de docentes por alunos $(\mathrm{U}=516, \mathrm{r}=-0,03)$ e o resultado do IDEB $(\mathrm{U}=424, \mathrm{r}=-0,08)$. Esses resultados demonstram que, apesar do grupo 3 ter realizado maiores investimentos e ter um número maior de escolas, o que justifica a diferença da eficiência apresentada, ele não conseguiu um resultado no IDEB significativamente diferente.

O comparativo entre os grupos 1 e 4 apresenta diferenças significativas entre docentes $(U=1.950$, $r=-0,47)$, escolas $(U=4.276, r=-0,24)$ e IDEB $(U=$ $1.978, r=-0,47)$. Não se encontrou uma diferença significativa entre os investimentos $(\mathrm{U}=5.937, \mathrm{r}=$ $-0,07)$ e eficiência ( $U=6.624, r=-0,01)$. O grupo 4 teve um resultado no IDEB superior ao grupo 1, 6,24 e 5,47, respectivamente, entretanto, as eficiências não foram diferentes, isso deve ter ocorrido pelo fato do grupo 4 ter um número maior de docentes e escolas.

Os grupos 2 e 3 não tiveram diferenças significativas na quantidade de docentes $(\mathrm{U}=736, \mathrm{r}=-0,04)$, todavia foram consideráveis em relação a investimentos ( $\mathrm{U}=$ 93, $\mathrm{r}=-0,26)$, escolas $(\mathrm{U}=0, \mathrm{r}=-0,29)$, IDEB (U= $345, r=-0,17)$ e eficiência $(U=6, r=-0,29)$. Apesar do grupo 3 ter realizado um maior investimento e ainda ter um número menor de escolas por aluno, seu resultado no IDEB e na eficiência foram inferiores aos do grupo 2.

$\mathrm{Na}$ comparação entre os grupos 2 e 4 todas as variáveis tiverem uma diferença significativa: (investimentos $(\mathrm{U}=2.381, \mathrm{r}=-0,56)$; números de docentes $(\mathrm{U}=$ 2.865, $\mathrm{r}=-0,52)$; escolas $(\mathrm{U}=3.363, \mathrm{r}=-0,48)$; IDEB $(\mathrm{U}=6.656, \mathrm{r}=-0,24)$; e eficiência $(\mathrm{U}=1.871, \mathrm{r}=$ -0,59). Ressalta-se que o grupo 4 realizaram um maior investimento, número menor de alunos por docente e um número maior de alunos por escola, gerando um resultado superior no IDEB em relação o grupo
2, o qual teve uma eficiência melhor na gestão dos recursos. O comparativo dos grupos entre os grupos 2 com o 4 relaciona-se com os achados de Rosano-Peña, Albuquerque e Márcio (2012), que identificaram uma correlação positiva entre os recursos disponibilizados e os resultados educacionais, mas somente quando não existem evidências de ineficiência, ou seja, uma maior alocação de insumos não garante melhores resultados se antes não se solucionar a ineficiência das unidades educacionais.

Por fim, a comparação entre os grupos 3 e 4 apresentou uma diferença significativa em investimentos $(\mathrm{U}=308$, $r=-0,18)$, escolas por alunos $(U=32, r=-0,28)$, IDEB $(\mathrm{U}=150,00, \mathrm{r}=-0,24)$ e eficiência $(\mathrm{U}=319, \mathrm{r}=-0,18)$. Entretanto, não se percebeu diferença significativa na variável docentes por alunos $(U=460, r=-0,13)$. Em linhas gerais, o grupo 4 teve um investimento menor e um número menor de escolas por alunos e obteve um resultado de IDEB e eficiência maior em relação ao grupo 3.

Por fim, como ponderam Moraes, Polizel e Crozatti (2017), há grupos de municípios que, mesmo gastando mais, não atingiram os melhores resultados, enquanto outros que empregaram de forma mais eficiente os recursos públicos obtiveram melhores resultados. Assim, a diferença da eficiência técnica (bcc) entre os grupos $2(75 \%)$ e $4(54 \%)$ pode estar relacionada ao tipo de retorno de escala que um município está operando, ou seja, quando uma unidade tomadora de decisão opera com retornos de escala decrescentes haverá um aumento proporcionalmente menor do produto em face do aumento nos fatores de produção.

\section{Considerações finais}

A presente pesquisa conseguiu identificar que o índice do IDEB dos municípios paranaenses foi em média de 5,89 , superior à meta estabelecida para o ano de 2015, que era de 5,49. Entretanto, 71 municípios não conseguiram atingir a meta. Quanto aos insumos, os índices médios foram os seguintes: investimentos por aluno, cerca de $\$ 5.685,00 ; 6,34$ alunos por professor e 145 alunos por escola. Já no que tange à eficiência, apenas 13 municípios podem ser enquadrados como eficientes, ou seja, apenas 3,3\%, uma vez que o principal problema dos municípios está ligado à eficiência técnica, a qual está relacionado à utilização dos insumos. 
Com o processo de análise das correlações, percebeu um relacionamento negativo fraco entre investimentos e escolas e positivo com docentes; já a eficiência possui um relacionamento negativo forte com investimentos e escolas e negativo fraco com docentes, como também um relacionamento positivo fraco com o IDEB.

Já a análise de agrupamentos demonstrou 4 grupos distintos de municípios que, através dos testes de comparativo de médias, apresentaram diferenças significativas. Além disso, as análises post hoc nãoparamétricas trouxeram contribuições importantes para a compreensão da problemática. Uma delas indica que há municípios que galgaram resultados melhores no IDEB com recursos menores e municípios que mesmo realizando um significativo aporte de recursos, não conseguiram obter bons resultados.

Deve-se considerar a existência de outros fatores que podem trazer luz às análises do desempenho educacional. Por exemplo Zoghbi et al, (2011) indicam que municípios mais populosos tendem a ser mais eficientes; Sousa, Magalhães e Nascimento (2016) apresentam indícios de um relacionamento estatisticamente significante entre o IDHM/educação, a eficiência na aplicação dos recursos públicos e o alcance da meta do IDEB; e Lourenço et al. (2017) e Trompieri Neto et al. (2009) dizem que os municípios podem ser diferenciados por aspectos sociais e pedagógicos, mais fortemente do que por aspectos econômicos financeiros, logo, os recursos financeiros em escolas municipais é desimportante, sendo apenas um dos elementos na promoção de uma educação de qualidade.

\section{Referências}

BEGNINI, S.; TOSTA, H. T. A Eficiência dos Gastos Públicos com a Educação Fundamental no Brasil: Uma Aplicação da Análise Envoltória de Dados (DEA). Revista Economia \& Gestão, v. 17, n. 46, p. 43-59, 2017.

BOGETOFT, P.; OTTO, L. Benchmarking with DEA. SFA and R. Springer, 2011.

BOHRER, É.; COMUNELO, A. L.; GODARTH, K. A. Eficiência do Gasto Público na Educação: O caso do Sudoeste do Paraná, Brasil. CAP

Accounting and Management, v. 7, n.7, p. 209222, 2013.
BOUERI, R. Modelos não paramétrico: Análise Envoltória de Dados (DEA) In: BOUERI, R.; ROCHA, F.; RODOPOULOS, F. (organizadores) Avaliação da Qualidade do Gasto Público e Mensuração da Eficiência. Brasília: Secretaria do Tesouro Nacional, 2015.

CASTRO, M. S.; SOUSA, E. P. Eficiência dos Gastos Públicos da Rede de Ensino Municipal Cearense.

Gestão \& Regionalidade, v. 34, n. 100, p. 92-109, 2018.

BRASIL. Constituição (1988). Constituição da República Federativa do Brasil. Brasília. Disponível em: < http://www.planalto.gov.br/ccivil_03/ Constituicao/Constituicao.htm>. Acesso em 20 de agosto de 2018.

\section{DANCEY, C. P., REIDY, J. Estatística sem} matemática para psicologia. Porto Alegre: Artmed. 2013.

DANTAS, F. da C.; COSTA, E. M.; SILVA, J. L. M. da. Eficiência nos gastos públicos em educação fundamental nos municípios do Rio Grande do Norte. Revista Econômica do Nordeste, Fortaleza, v. 46, n. 1, p. 27-40, jan.-mar., 2015

DIEL, E. H.; DIEL, F. J.; SCHULZ, S. J.; CHIARELLO, T. C.; ROSA, F. S. da. Desempenho de municípios brasileiros em relação à estratégia de investimento público em educação.

Desenvolvimento em Questão, v. 26, p. 79-107, abr./jun., 2014.

DINIZ, J. A.; CORRAR, L. J.. Análise da Relação entre a Eficiência e as Fontes de Recursos dos Gastos Municipais no Ensino Fundamental. Sociedade, Contabilidade e Gestão, v. 6, n. 1, 2011.

BRASIL. Constituição (1988). Emenda Constitucional $\mathrm{n}^{\circ}$ 14, de setembro de 1996. Disponível em: < http://www.planalto.gov.br/ ccivil_03/constituicao/emendas/emc/emc14.htm>. Acesso em 20 de agosto de 2018.

FERNANDES, R. Índice de Desenvolvimento da Educação Básica (Ideb). Brasília: Instituto Nacional de Estudos e Pesquisas Educacionais Anísio Teixeira, 2007

FERREIRA, C. M.de C.; GOMES, A. P. Introdução à análise envoltória de dados: teoria, modelos e aplicações. Viçosa: Editora UFV, 2009. 
FIELD, A. Descobrindo a Estatística usando o SPSS. São Paulo: Artmed, 2009.

HAIR,J. F.;BLACK, W. C.; BABIN, B.J.; ANDERSON, R. E.; TATHAM, R. L. Análise multivariada de dados. 6. ed. Porto Alegre: Bookman, 2009.

IBGE. Bases Cartográficas. Disponível em: <https:/ / mapas.ibge.gov.br/bases-e-referenciais/basescartograficas.html>. Acesso em 12 agosto de 2018

INEP. Ministério da Educação. Disponível em: $<$ http://www.enem.inep.gov.br/>. Acessado em 20 de agosto de 2018.

KAVESKI, I. D. S.; MARTINS, J. A. S.; SCARPIN, J. E. A eficiencia dos gastos publicos com o ensino médio regular nas instituições estaduais brasileiras. Enfoque, v. 34, n. 1, p. 29-43, 2015.

LOURENÇO,R.L.;ANGOT'TI,M.;NASCIMENTO, J. C. H. B. do; SAUERBRONN, F. F. Eficiência do gasto público com ensino fundamental: uma análise dos 250 maiores municípios brasileiros. Revista Contabilidade Vista e Revista, v. 28, n. 1, p. 89-116, jan/jun. 2017.

LOURENÇO, R. L.; NASCIMENTO, J. C. H. B.; SAUERBRONN, F. F.; MACEDO, M. A. S. Determinantes Sociais e Pedagógicos das Notas do IDEB. Revista Pensamento Contemporâneo em Administração, v. 11, n. 4, p. 27-43, 2017.

MACHADO JR., S. P.; IRFFI, G.; BENEGAS, M. Análise da eficiência técnica dos gastos com educação, saúde e assistência social dos municípios cearenses. Planejamento e Políticas Públicas, Brasília, n. 36, p. 87-113, jan./jun. 2011.

MATTOS, E.; TERRA, R. Conceitos sobre eficiência. In: BOUERI, R.; ROCHA, F.; RODOPOULOS, F. (organizadores) Avaliação da qualidade do gasto público e mensuração da eficiência. Secretaria do Tesouro Nacional: Brasília, 2015a.

MATTOS, E.; TERRA, R. Fundamentos microeconômicos da mensuração da eficiência. In: BOUERI, R.; ROCHA, F; RODOPOULOS, F. (org.) Avaliação da qualidade do gasto público e mensuração da eficiência. Secretaria do Tesouro Nacional: Brasília, 2015b.
MONTE, M. M.; LEOPOLDINO, C. B. Eficiência dos Gastos Municipais em Educação no Ceará. Revista Pensamento Contemporâneo em Administração, v. 11, n. 4, p. 44-55, 2017.

MORAES, V. M. DE; POLIZEL, M. F; CROZATTI, J. Eficiência dos gastos municipais com a educação fundamental: uma análise dos municípios paulistas no ano de 2013. RC\&C - Revista Contabilidade e Controladoria, Curitiba, v. 9, n. 2, p. 23-43, mai./ago. 2017.

PASCOTTO, H.; COMUNELO, A. L.; CERETTA, G. F., Eficiência técnica na aplicação de recursos públicos na área da saúde dos municípios do sudoeste do Estado do paraná. Gestão e Desenvolvimento em Revista. v. 4, n. 1, jan-jun/2018, p. 21-37.

ROCHA, F.; DUARTE, J.; GADELHA, S. R. de B; OLIVEIRA, P. P. de; PEREIRA, L. F. V. N. É possível atingir as metas para a educação sem aumentar os gastos? Uma análise para os municípios brasileiros. Textos para Discussão do Tesouro Nacional. nro.15. 2013

ROSANO-PEÑA, C. Eficiência e impacto do contexto na gestão através do DEA: o caso da UEG. Produção, Brasília, DF, v. 22, n. 4, p. p. 778-787, set./ dez. 2012.

ROSANO-PEÑA, C. Um Modelo de Avaliação da Eficiência da Administração Pública Através do Método Análise Envoltória de Dados (DEA). RAC - Revista de Administração Contemporânea, Curitiba, v. 12, n. 1, p. 83-106, jan./mar. 2008.

ROSANO-PEÑA，C.; ALBUQUERQUE，P. H. M.; MÁRCIO, C. J. A eficiência dos gastos públicos em Educação: evidências georreferenciadas nos municípios goianos. Economia Aplicada, v.16, n.3, 2012.

SAVIAN, M. P. G.; BEZERRA, F. M. Análise de eficiência dos gastos públicos com educação no ensino fundamental no estado do Paraná. Economia \& Região, v.1, n.1, p. 26-47, jan./jul. 2013.

SCHUSTER, H. A.; ZONATTO, V. Evidências da Eficiência de Gastos Públicos na Alocação dos Recursos Destinados ao Ensino Fundamental nos Estados Brasileiros. Contextus - Revista Contemporânea de Economia e Gestão, v. 15, n. 2, p. 8-33, 2017. 
SENRA, N.; MELLO, S. de; MEZA, A. Estudo sobre métodos de seleção de variáveis em DEA. Pesquisa Operacional, v.27, n.2, p.191-207, mai./ago., 2007.

SILVA FILHO, G. M. da; PEREIRA, T. R. L.; DANTAS, M. G. da S.; ARAÚJO, A. O. Análise da eficiência nos gastos públicos com educação fundamental nos colégios militares do exército em 2014. Revista Evidenciação Contábil \& Finanças, v. 4, n. 1, p. 50-64, jan./abr., 2016.

SILVA, A. A. P.; FERREIRA, M. A. M.; BRAGA, M. J.; ABRANTES, L. A. Eficiência na alocação de recursos públicos destinados à educação, saúde e habitação em municípios mineiros. Contabilidade, Gestão e Governança, v. 15, n. 1, p. 96-114, 2012.

SILVA, A. B.; NASCIMENTO, J. C. H. B. do; FERREIRA, A. da C. S.; LIMA, J. R. F. Accountability para a Gestão de Verbas da Educação Pública em Municípios Brasileiros: Análise com Envoltória de Dados (DEA). Revista Iberoamericana de Contabilidad de Gestión, v.12, p.1-16, 2015.

SILVA, J. L. M.; ALMEIDA, J. C. L. Eficiência no gasto público com educação: uma análise dos municípios do Rio Grande do Norte. Planejamento e Políticas Públicas, n. 39, 2012.

SILVA, M. C. da; SOUZA; F. J. V. de; BORGES, E. F.; ARAÚJO, A. O.; SILVA, J. D. G. da. Avaliação da função educação nos municípios de São Paulo, Rio de Janeiro e Belo Horizonte: mudança ou inércia social?. ConTexto, Porto Alegre, v. 15, n. 29, p. 17-29, jan./ abr. 2015.

SOUSA, A. N. G. de; RUTALIRA, J. J. B. Eficiência do gasto público em educação de nível fundamental: uma análise dos estados brasileiros. Interface - Revista do Centro de Ciências Sociais Aplicadas, v. 13, n. 1, p. 33-50, 2016.

SOUSA, W. D.; MAGALHÃES, M. A.; NASCIMENTO, J. C. H. B.; BERNARDES, J. R. Análise dos Gastos na Alocação dos Recursos Públicos Destinados ao Ensino Fundamental dos Munícipios do Espírito Santo. GESTÃO.Org Revista Eletrônica de Gestão Organizacional, v. 14, n. 2, p. 381-392, 2016.

SOUZA, F. J. V.; MELO, M. M. D. de; SILVA, M. C. da; ARAÚJO, A. O. Alocação de Recursos Públicos em Educação nos Estados Brasileiros. Revista Uniabeu, v. 5, n. 11, p. 155-170, 2012.
TROMPIERI NETO, N.; LOPES, DANIEL A. F; BARBOSA, M. P. HOLANDA, M. C. Determinantes da eficiência dos gastos públicos municipais em educação e saúde: o caso do Ceará. In: CARVALHO, E. B. S.; HOLANDA, M. C.; BARBOSA, M. P. (Orgs.). Economia do Ceará em Debate. Fortaleza: IPECE, 2009. p.57-72.

WILBERT,M.D.; D’ABREU,E.C.C. F.; Eficiência dos gastos públicos na educação: análise dos municípios do estado de alagoas. Advances in Scientific and Applied Accounting, v. 6, n. 3, p. 348-372, 2013.

ZOGHBI, A. C. P.; ROCHA, F. F.; MATOS, E. H. C. de; ARVATE, P. R. SOUSA, W. D.; MAGALHÃES, M. A.; NASCIMENTO, J. C. H. B.; BERNARDES, J. R. Análise dos Gastos na Alocação dos Recursos Públicos Destinados ao Ensino Fundamental dos Munícipios do Espírito Santo. Revista Gestão. Org., v. 14, n. 2, 2016. p. 381-392Planejamento e políticas públicas, n. 36, p. 9-61, jan./jun., 2011. 